\title{
Organization and Reorganization of Neuromuscular Junctions in Mice Lacking Neural Cell Adhesion Molecule, Tenascin-C, or Fibroblast Growth Factor-5
}

\author{
Lisa M. Moscoso, ${ }^{1}$ Harold Cremer, ${ }^{2}$ and Joshua R. Sanes ${ }^{1}$ \\ ${ }^{1}$ Department of Anatomy and Neurobiology, Washington University School of Medicine, St. Louis, Missouri 63110, and \\ 2Developmental Biology Institute of Marseille, Campus de Luminy Case 907, 13288 Marseille Cedex 9, France
}

\begin{abstract}
Many proteins have been hypothesized to mediate intercellular interactions that regulate the formation, maturation, and maintenance of the skeletal neuromuscular junction. Three of the best characterized of these are a membrane-associated adhesion molecule, neural cell adhesion molecule ( $\mathrm{N}-\mathrm{CAM}$ ), an extracellular matrix component, tenascin- $\mathrm{C}$, and a soluble growth factor, fibroblast growth factor- 5 (FGF-5). To assess the roles of these molecules in synaptogenesis in vivo, we examined neuromuscular junctions in homozygous mutant mice lacking $\mathrm{N}-\mathrm{CAM}$, tenascin-C, FGF-5, or both N-CAM and tenascin-C. End plates were $14 \%$ smaller in N-CAM-deficient mice than in controls, and formation of junctional folds was delayed in this
\end{abstract}

mutant. In all other respects tested, however, the structure and molecular architecture of neuromuscular junctions were normal in all three single mutants and in the double mutant. We also tested the abilities of damaged motor axons to reinnervate mutant muscle after axotomy and of intact motor axons to sprout after partial denervation. Again, no significant differences among genotypes were observed. Together, these results demonstrate that $\mathrm{N}-\mathrm{CAM}$, tenascin-C, and FGF-5 are dispensable for major aspects of synaptic development and regeneration.

Key words: FGF; neuromuscular junction; N-CAM; reinnervation; sprouting; synapse formation; tenascin
The formation of the neuromuscular junction (NMJ) requires numerous interactions between presynaptic and postsynaptic cells (for review, see Hall and Sanes, 1993). Genetic studies in mice have recently provided support for the candidacy of two proteins, agrin and neuregulin/ARIA, as nerve-derived mediators of postsynaptic differentiation (Gautam et al., 1996; Sandrock et al., 1997). Although other signals are undoubtedly involved, agrin and neuregulin along with synaptic transmission (i.e., electrical activity) per se, may account for much of the synaptogenetic effect of nerve on muscle (for review, see Sanes, 1997).

In contrast, less is known about the retrograde signals that muscles use to regulate the behavior of motor axons. Several candidates have been proposed, primarily on the basis of their patterns of expression in vivo and their bioactivities in vitro. These include membrane-bound cell adhesion molecules such as the neural cell adhesion molecule (N-CAM), basal lamina components such as laminin- $\beta 2$, interstitial matrix molecules such as tenascin- $\mathrm{C}$, and soluble growth factors such as fibroblast growth factor-5 (FGF-5). Evidence that laminin- $\beta 2$ is a crucial organizer of presynaptic differentiation in vivo comes from the observation that NMJs in mutant mice lacking this protein exhibit aberrant nerve terminals, impaired synaptic transmission, severe weakness, and an impaired ability to regenerate after injury (Noakes et al., 1995) (B. L. Patton and J. R. Sanes, unpublished observations). The purpose of the studies reported here was to test the

\footnotetext{
Received Oct. 14, 1997; revised Nov. 20, 1997; accepted Nov. 26, 1997.

This work was supported by grants from the National Institutes of Health. We thank Jeanette Cunningham and Mia Nichol for expert assistance.

Correspondence should be addressed to Dr. Joshua R. Sanes, Department of Anatomy and Neurobiology, Washington University School of Medicine, Box 8108, 660 South Euclid Avenue, St. Louis, MO 63110.

Copyright (c) 1998 Society for Neuroscience $0270-6474 / 98 / 181465-13 \$ 05.00 / 0$
}

candidacies of N-CAM, tenascin-C, and FGF-5 by analyzing NMJs in mice bearing null mutations in the cognate genes.

$\mathrm{N}-\mathrm{CAM}$ is an abundant cell adhesion molecule that is present on axons of numerous types of developing and adult neurons, including motoneurons (Goridis and Brunet, 1992). N-CAM is also expressed by muscle cells, and this expression is regulated in remarkable parallel with muscle susceptibility to innervation. $\mathrm{N}-\mathrm{CAM}$ is found throughout the myotube surface in the developing embryo, when synaptic contacts form. Postnatally, N-CAM levels decrease extrasynaptically as synapses mature and these portions of the muscle fiber surface become refractory to innervation; in adult muscle, N-CAM is primarily confined to the postsynaptic membrane. After denervation or paralysis, when muscle fibers become susceptible to reinnervation, N-CAM reappears on the surface of the myofiber. With reinnervation, as muscle fibers again become refractory to hyperinnervation, levels of N-CAM decrease extrasynaptically, and only synaptic expression persists (Covault and Sanes, 1985, 1986; Moore and Walsh, 1985; Rieger et al., 1985; Sanes and Covault, 1985; Covault et al., 1986). Because N-CAM is predominantly a homophilic adhesion molecule, this pattern of expression suggested the hypothesis that $\mathrm{N}-\mathrm{CAM}$ on the motor axon could interact with $\mathrm{N}-\mathrm{CAM}$ on muscle surfaces to regulate synaptogenesis. In support of this idea, anti-N-CAM inhibited interactions of neuronal somata and myotubes in nerve-muscle cocultures (Rutishauser et al., 1983) and reduced the outgrowth of neurites on myotubes, especially when applied in combination with antibodies to other adhesion molecules (Bixby and Reichardt, 1987; Bixby et al., 1987). Treatment of denervated frog (Rieger et al., 1988) or mouse muscles (Langenfeld-Oster et al., 1994) with anti-N-CAM in vivo resulted in a delay in reinnervation. In rats, application of antibodies to $\mathrm{N}-\mathrm{CAM}$ decreased the extent of nerve sprouting after paralysis of the muscle with botulinum toxin (Booth et al., 1990). Together, 
these results supported the idea that N-CAM regulates nervemuscle interactions.

Comparable studies of expression and bioactivity in vivo and in vitro also implicated tenascin-C in neuromuscular development. Tenascin- $\mathrm{C}$ is a glycoprotein component of the extracellular matrix that was originally isolated as an antigen associated with myotendinous junctions (Chiquet and Fambrough, 1984) but was later shown to be a more widely expressed molecule with both adhesive and antiadhesive properties (Götz et al., 1996). During early development, tenascin-C is expressed in the limb bud in patterns that suggested a role in guiding nerves to their targets (Martini and Schachner, 1991; Wehrle-Haller et al., 1991). After denervation of adult muscle, tenascin levels increase in perisynaptic fibroblasts and Schwann cells (Sanes et al., 1986; Daniloff et al., 1989; Gatchalian et al., 1989; Weis et al., 1991). Substratebound tenascin-C is antiadhesive to some cells but promotes neurite outgrowth by sensory and motoneurons in vitro (Wehrle and Chiquet, 1990; Wehrle-Haller and Chiquet, 1993). Finally, antibodies to tenascin-C delay reinnervation in both frog and mouse muscle in vivo (Mège et al., 1992; Langenfeld-Oster et al., 1994). These studies support the hypothesis that tenascin-C and $\mathrm{N}-\mathrm{CAM}$ might be involved in related neuromuscular interactions.

Finally, muscles are believed to secrete soluble "trophic" factors that regulate the behavior of motor axons, and recent studies suggest that FGFs may be such factors. FGFs are a family of $>10$ structurally related, secreted polypeptides that regulate proliferation, growth, and differentiation of many tissues, including nerve and muscle (Hannon et al., 1996; Ozawa et al., 1996). Several FGFs (FGF-1, -2, and -4-8) are expressed in developing skeletal muscle (Olwin et al., 1994; Hannon et al., 1996), and motoneurons express FGF receptors (Wanaka et al., 1990). In vitro, FGFs support the survival of chick and rat spinal motoneurons (Hughes et al., 1993a,b), stimulate neurite outgrowth from ciliary motoneurons (Gurney and Yamamoto, 1991), and promote differentiation of functional motor nerve terminals (Dai and Peng, 1995). Administration of FGFs in vivo reverses neurochemical effects of axotomy on spinal motoneurons (Li et al., 1994; Piehl et al., 1995), rescues motoneurons in mice with a motoneuron disease (Ikeda et al., 1995), and promotes formation of sprouts from motor nerve terminals on skeletal muscle fibers (Gurney et al., 1992). Because most of the FGFs bind to all of the four known FGF receptors (Ornitz et al., 1996), one would expect that any of several musclederived FGFs could mediate retrograde effects on motoneurons. However, studies by Hughes et al. (1993a,b) and Lindholm et al. (1994) indicated a specific role for FGF-5 in these processes. Hughes et al. (1993a) showed that $\sim 65 \%$ of the total motoneuron survival activity extractable from embryonic rat skeletal muscle was immunoprecipitated by an antiserum to FGF-5. The antiserum was highly specific for FGF-5 and was demonstrably nonreactive with at least FGF-1, -2 , and -4 . Subsequently, Hughes et al. (1993b) showed that FGF-5 was more potent than FGF-2 in promoting survival of rodent motoneurons, and Lindholm et al. (1994) showed that FGF-5 increased choline acetyltransferase activity of cultured cholinergic neurons from brain. Thus, although muscles may provide numerous soluble growth factors to motor axons (Oppenheim, 1996), these results suggested that FGF-5 might play a prominent role.

In light of these studies, it came as a surprise to many neurobiologists that null mutants of N-CAM (Cremer et al., 1994), tenascin-C (Saga et al., 1992; Steindler et al., 1995; Forsberg et al., 1996; Settles et al., 1997), and FGF-5 (Hébert et al., 1994) were all viable and fertile and, therefore, clearly had functional NMJs.
Indeed, no neural defects at all have been found in tenascin- $\mathrm{C}$ and FGF-5 mutants, and only subtle defects have been found in the brain of N-CAM mutants (Cremer et al., 1994, 1997; Ono et al., 1994). However, the neuromuscular system was not examined in the initial studies of these mice. It therefore remained possible that (1) the mutants harbored neuromuscular defects that compromised synaptic structure without preventing synaptic transmission; (2) synaptogenesis might be delayed in the mutants; or (3) the ability of the mutant neuromuscular system to respond to stresses such as denervation might be compromised. To explore these possibilities, we looked in detail at the size, shape, and molecular architecture of NMJs in N-CAM, tenascin-C, and FGF-5 mutants. We also tested the ability of motor axons to elaborate sprouts in response to partial denervation (in all three mutants and in an N-CAM/tenascin-C double mutant), to reinnervate denervated muscle (in N-CAM and tenascin-C mutants and in the double mutant), and to mature on schedule (in N-CAM mutants). In no case did we find severe abnormalities, suggesting that N-CAM, tenascin-C, and FGF-5 are all dispensable for qualitatively normal development and regeneration of NMJs.

\section{MATERIALS AND METHODS}

Mice. N-CAM-deficient mice were generated by Cremer et al. (1994). Tenascin-C-deficient mice were generated by Saga et al. (1992) and were generously provided by Dr. S. Aizawa (Kumamoto University School of Medicine, Kumamoto, Japan). Pathogen-free colonies of both mutants were derived via a single outcross of homozygous mutant mice with C57BL/6 females (The Jackson Laboratory, Bar Harbor, ME). Offspring were delivered under aseptic conditions via cesarean section and transferred to foster mothers in a barrier facility. Subsequent progeny were genotyped by PCR using primers that distinguished wild-type from mutant alleles. FGF-5-deficient mice (originally called angora; Hébert et al., 1994) were obtained from The Jackson Laboratory and maintained as homozygotes or mated to C57BL/6 mice.

Surgery. Mice were anesthetized with ketamine $(8.7 \mathrm{mg} / 100 \mathrm{gm})$ and xylazine $(13 \mathrm{mg} / 100 \mathrm{gm})$ and placed supine under a dissecting microscope. The neck was shaved, and a vertical incision was made from the chin to the superior aspect of the sternum. Skin and salivary glands were retracted to allow access to the nerve of the sternomastoid. To denervate the sternomastoid completely, its nerve was crushed with a forceps just lateral to its point of entry into the muscle. Denervation was assessed visually by noting contractions of the muscle on nerve crush and subsequent transparency of the crushed portion of the nerve. To prolong denervation, the nerve to the sternomastoid was crushed at days 0 and 3 and allowed to recover until day 7. Alternatively, a $1-2 \mathrm{~mm}$ portion of the sciatic nerve was removed via an incision made in the upper thigh, and lower leg muscles were taken on day 2 or 7 . For partial denervation, animals were prepared as above, and a tungsten needle was inserted into the nerve to the sternomastoid to split it in half. One-half of the nerve was then severed using a microknife. This procedure ensured that regeneration of damaged axons was delayed, so that sprouting by intact axons could be observed uncomplicated by reinnervation. In all cases, incisions were closed with sutures or staples.

Light microscopy. For immunohistochemical studies of adult NMJs, lower leg muscles from innervated and denervated animals were dissected, frozen without fixation in liquid nitrogen-cooled isopentane, and sectioned at $4-8 \mu \mathrm{m}$ in a cryostat. Sections were mounted on gelatincoated slides. Sections were then incubated with primary antibody at $4^{\circ} \mathrm{C}$ overnight or at room temperature for $3 \mathrm{hr}$, washed for $30 \mathrm{~min}$, labeled with second antibody for $1 \mathrm{hr}$ at room temperature, washed again for 30 min, mounted with paraphenyldiamine and glycerol, and viewed with epifluorescence optics.

Antibodies to the following antigens were used: mouse N-CAM, recombinant heregulin (a gift of M. Slikowski, Genentech, San Francisco, CA), laminin- $\beta 2$ (JS1), neu/erbB2 (sc-284; Santa Cruz Biotechnology, Santa Cruz, CA), erbB3 (sc-285; Santa Cruz Biotechnology), laminin-1 and S-100 (Dako, Carpinteria, CA), neurofilaments (Sternberger Monoclonals, Baltimore, MD), synaptophysin (a gift of A. Czernik and P. Greengard, Rockefeller University), agrin (a gift of Z. Hall, National Institutes of Health), SV2 (a gift of K. Buckley, Harvard University), dystrophin, utrophin, and rapsyn (Moscoso et al., 1995; Noakes et al., 
1995; Gautam et al., 1996). Fluorosceinated and rhodaminated second antibodies and lectins were obtained from Boehringer Mannheim (Indianapolis, IN) and Sigma (St. Louis, MO).

To assay reinnervation and sprouting, animals were killed using an overdose of sodium pentobarbitol and then perfused through the heart with Ringer's solution followed by $2 \%$ paraformaldehyde in PBS. The vertical incision in the neck was reopened, and the soft tissue of the neck was bathed in $2 \%$ paraformaldehyde for $15 \mathrm{~min}$. The sternomastoid muscle was removed, rinsed in PBS, sunk in $30 \%$ sucrose, mounted in embedding medium, and frozen in liquid nitrogen-cooled isopentane. Longitudinal sections were cut $40 \mu \mathrm{m}$ thick with a cryostat and mounted on gelatin-coated slides. Sections were post-fixed in ice-cold methanol for 10 min and stained with anti-neurofilament, anti-synaptophysin, and rhodaminated $\alpha$-bungarotoxin (Molecular Probes, Eugene, OR). To view Schwann cell processes, sections were stained with anti-S-100 and rhodamine $-\alpha$ bungarotoxin. To measure end plate size, images of rhodamine- $\alpha$ bungarotoxin-labeled end plates were captured using a cooled CCD camera (Photometrics, Tucson, AZ). The major diameter of each end plate was measured using IPLab software (Signal Analytics, Vienna, VA). Similar methods were used to measure the length of Schwann cell processes.

Electron microscopy. Animals were killed as above and perfused with Ringer's solution followed by $4 \%$ paraformaldehyde and $4 \%$ glutaraldehyde in $150 \mathrm{~mm}$ cacodylate buffer, $\mathrm{pH}$ 7.2. Sternomastoid muscles were dissected, fixed overnight at $4^{\circ} \mathrm{C}$, washed, and stained lightly for acetylcholinesterase using the method of Karnovsky and Roots (1964) to facilitate location of end plates. The end plate-rich region of the muscle was refixed in $1 \% \mathrm{OsO}_{4}$ in cacodylate buffer, dehydrated, and embedded in Araldite. Thin sections were stained with uranyl acetate and lead citrate and viewed in a JEOL 1200 electron microscope.

\section{RESULTS}

\section{N-CAM mutants}

\section{Structure of the adult NMJ}

To begin this study, we compared the size and shape of NMJs in longitudinal sections from sternomastoid muscles of adult $\mathrm{N}-\mathrm{CAM}^{-/-}$and control mice. Nerve terminals were marked by a mixture of antibodies to neurofilaments and synaptophysin. Neurofilments are abundant in motor axons, and synaptophysin is a major component of the synaptic vesicles that are concentrated in the nerve terminal. Thus, the combination of these two antibodies revealed both the preterminal axons and their terminal arbors (Gautam et al., 1996). To stain the postsynaptic membrane, sections were incubated with rhodaminated $\alpha$-bungarotoxin, which binds specifically and tightly to ACh receptors (AChRs).

A typical end plate from an adult wild-type mouse is shown in Figure $1 a, a^{\prime}$. A single axon contacts each muscle fiber, branches, and terminates on the muscle fiber surface in a circumscribed spray of varicose branches (Fig. 1a). AChRs are concentrated in the postsynaptic membrane in a pretzel-like pattern with distinct boundaries (Fig. 1 $a^{\prime}$ ). Presynaptic and postsynaptic structures overlap completely. NMJs in $\mathrm{N}-\mathrm{CAM}^{-/-}$mice were similar in shape and complexity to those in the wild-type mouse, and, as in controls, mutant presynaptic and postsynaptic structures were completely apposed (Fig. 1b, $b^{\prime}$ ). Morphometric analysis revealed, however, that mutant end plates were smaller than controls. A difference was seen in each of four age-matched pairs of animals (Fig. 1c). When data from all animals were combined, the difference was $14 \%$, which was statistically significant $(p<0.001$, Student's $t$ test). However, it has been noted that N-CAM mutant mice weigh $\sim 10 \%$ less than their wild-type littermates (Cremer et al., 1994) and might therefore be expected to have 2-3\% smallerdiameter myofibers. Because end plate size is proportional to myofiber diameter (Balice-Gordon and Lichtman, 1993) the difference that we observe may reflect partially the overall size of the mutant animals.

To assess synaptic ultrastructure, muscles were prepared for electron microscopy, and NMJs were observed in thin sections.
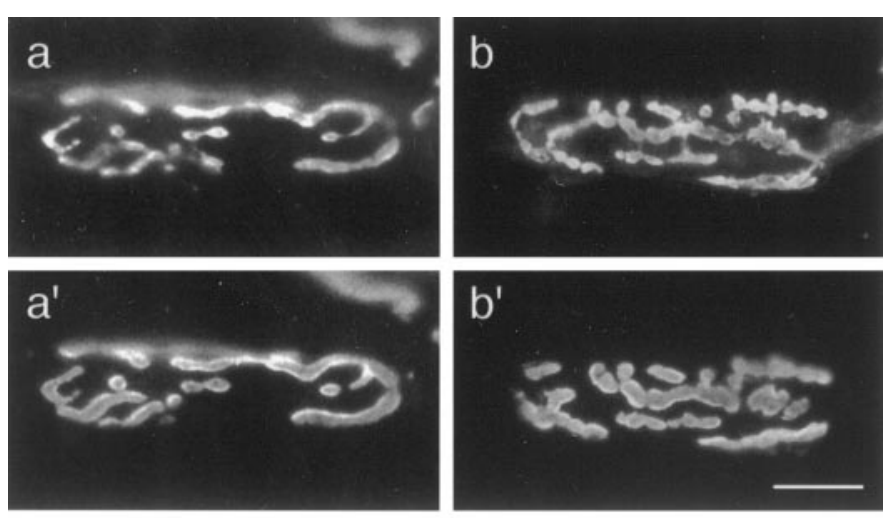

C

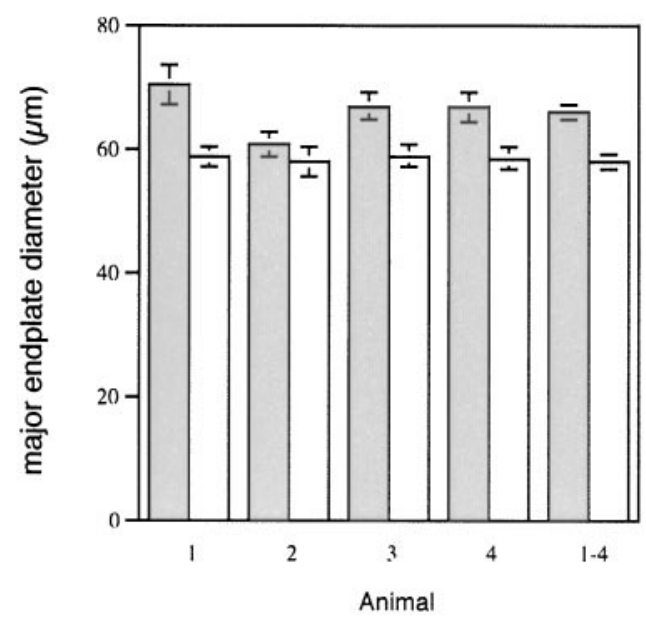

Figure 1. Size and shape of NMJs in adult wild-type and N-CAM ${ }^{-1-}$ mice. Longitudinal cryostat sections of sternomastoid muscles from control $\left(a, a^{\prime}\right)$ and $\mathrm{N}-\mathrm{CAM}^{-/-}\left(b, b^{\prime}\right)$ mice were stained with a mixture of fluorescein-tagged anti-neurofilament and anti-synaptophysin to label preterminal and terminal portions of the motor axon, plus rhodamine$\alpha$-bungarotoxin to label AChRs concentrated in the postsynaptic membrane. The sections were viewed through filters selective for fluorescein $(a, b)$ or rhodamine $\left(a^{\prime}, b^{\prime}\right)$. At both wild-type and mutant end plates, the terminal branches of the axon directly overlie postsynaptic specializations. $c$, Average length of NMJs. Each bar represents measurements of the major diameter (parallel to the long axis of the muscle fiber) from 50 end plates (mean \pm SEM) in the sternomastoid of a single animal. The first four pairs of bars show data from age-matched $\mathrm{N}-\mathrm{CAM}^{-1-}$ (open bars) and control (closed bars) muscles. All data are combined in the last pair of bars. Mutant end plates are smaller than controls $(p<0.001$, Student's $t$ test). Scale bar, $20 \mu \mathrm{m}$.

Three cells (motoneuron, muscle fiber, and terminal Schwann cells) contribute to the NMJ. Each of these cells is specialized at the synapse. The nerve terminal is densely packed with synaptic vesicles, which are clustered at active zones, whereas the preterminal axon contains few vesicles and no active zones. The terminal Schwann cell extends thin processes to cap the nerve terminal, whereas preterminal Schwann cells form myelin. The postsynaptic membrane of the muscle fiber is thrown into $\sim 1$ - $\mu$ m-deep folds at the synapse, which are absent extrasynaptically (Fig. 2a). In all of these respects, mutant NMJs were indistinguishable from their wild-type counterparts (Fig. 2b).

\section{Molecular architecture}

Although the structure of the NMJ appeared normal in $\mathrm{N}-C A M^{-/-}$mutants, its molecular composition might have been perturbed. To test this possibility, we stained wild-type and mu- 

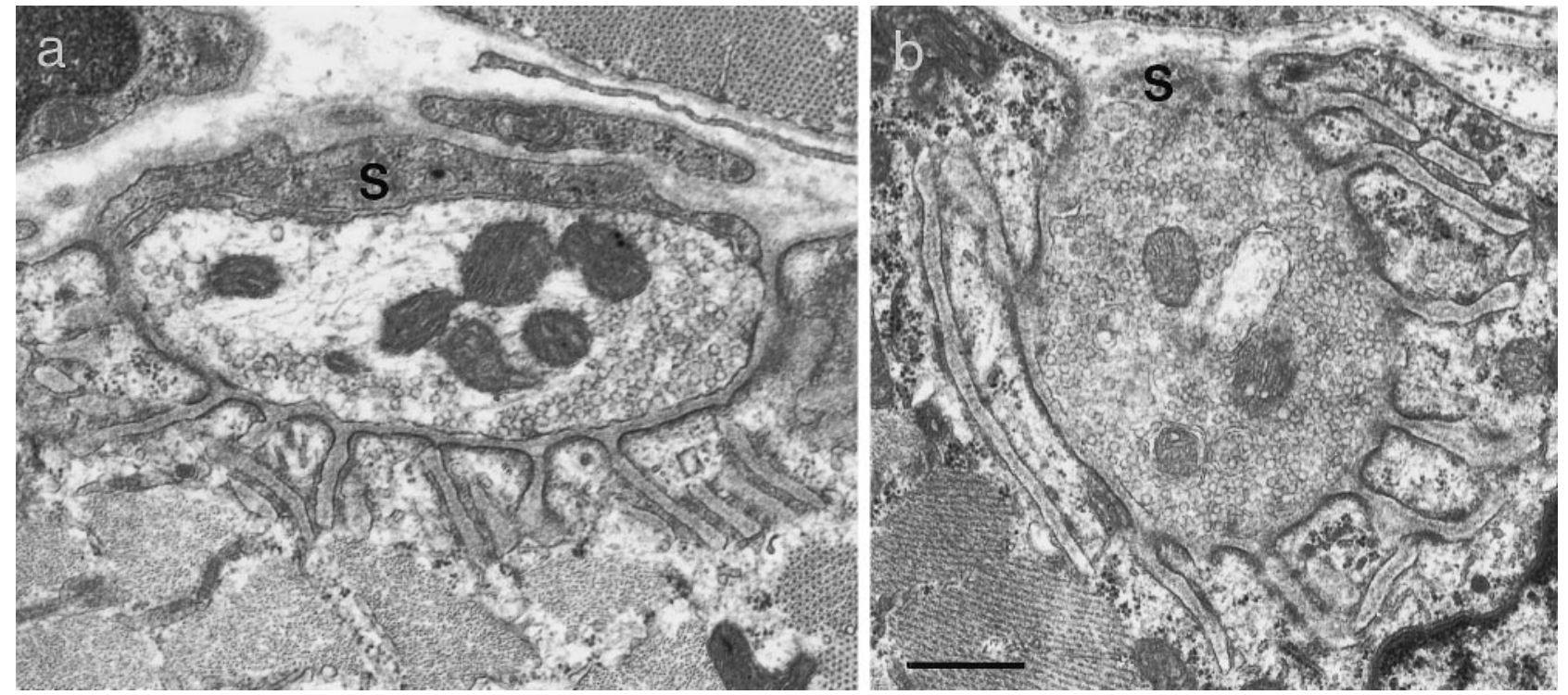

Figure 2. Electron micrographs of NMJs from adult control $(a)$ and $\mathrm{N}-C A M^{-1-}(b)$ mice. In both, a vesicle-laden nerve terminal is capped by processes of a Schwann cell $(S)$ and overlies the enfolded postsynaptic membrane of the muscle fiber. Scale bar, $0.5 \mu \mathrm{m}$.
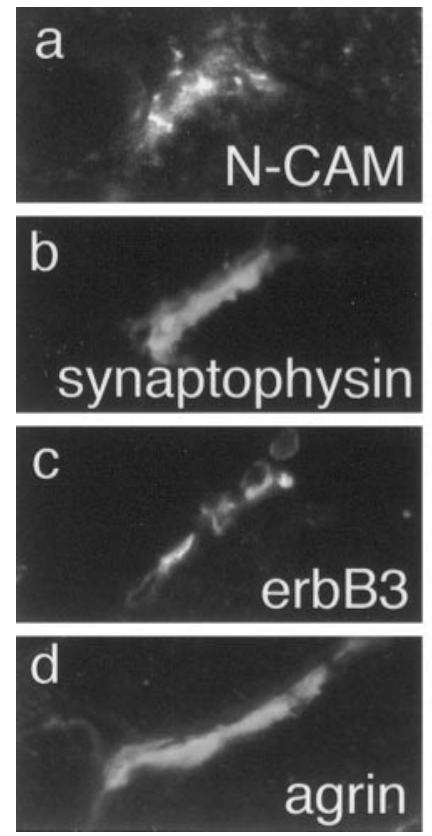
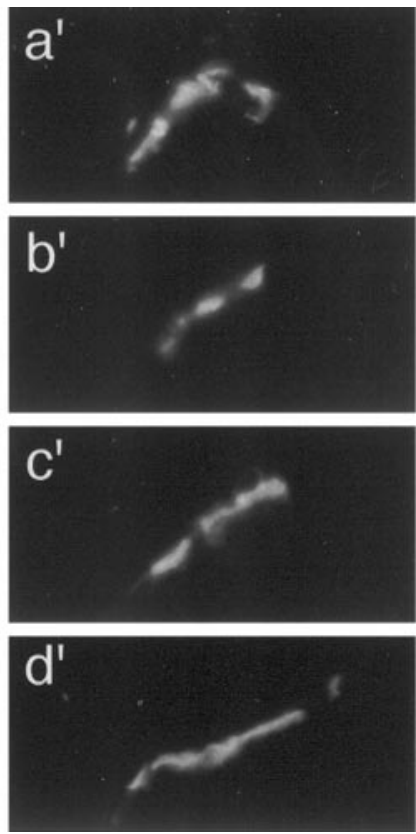
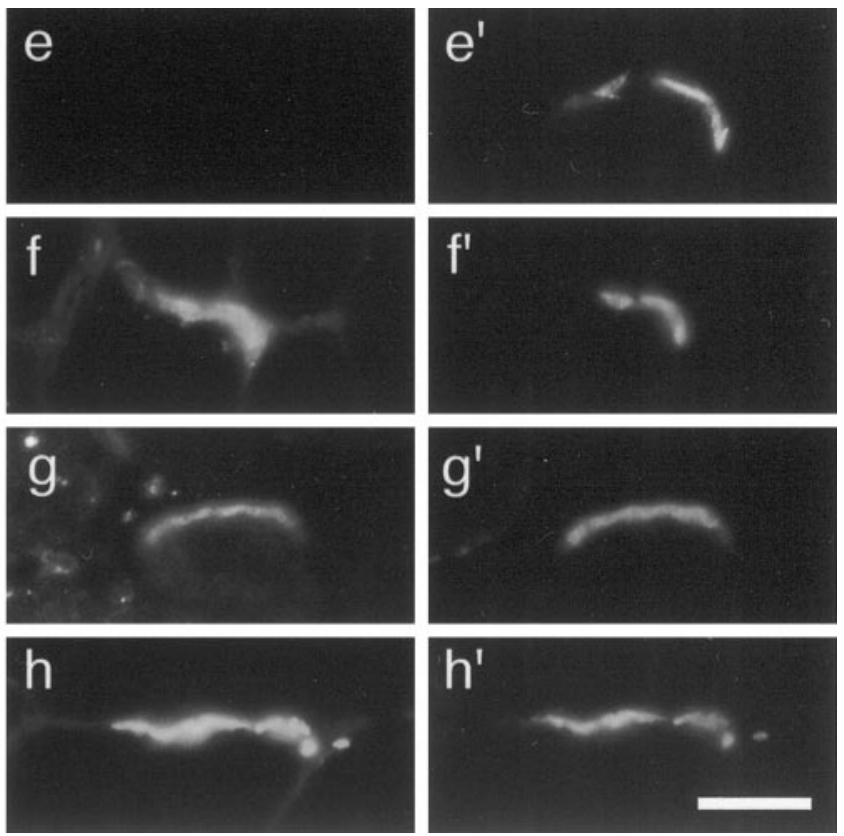

Figure 3. Distribution of synaptic antigens at NMJs in control $(a-d)$ and N-CAM ${ }^{-1-}(e-h)$ mice. Cross-sections of hindlimb muscles were doubly stained with antibodies to N-CAM $(a, e)$, synaptophysin $(b, f)$, erbB3 $(c, g)$, or agrin $(d, h)$ plus rhodamine- $\alpha$-bungarotoxin $\left(a^{\prime}-h^{\prime}\right)$. Mutant end plates were devoid of N-CAM, as expected, but did not otherwise differ from controls. Scale bar, $10 \mu \mathrm{m}$.

tant muscle with a panel of antibodies and histological stains specific for 13 antigens concentrated at the NMJ. Two of the antibodies recognized synaptophysin and SV2, major components of synaptic vesicles (Calakos and Scheller, 1996). Three antibodies were directed against components of the synaptic basal lamina: laminin $\beta 2$, agrin, and neuregulin (Sanes, 1995). Two other components of the basal lamina were revealed histochemically: acetylcholinesterase by an enzymatic stain (Karnovsky and Roots, 1964) and $N$-acetylgalactosaminyl-terminated carbohydrate by a lectin, Vicia villosa agglutinin B4 (VVA-B4) (Scott et al., 1988). Three antibodies were specific for components of the postsynaptic membrane: erbB2, erbB3, and integrin $\alpha 7 \mathrm{~A}$ (Mos- coso et al., 1995; Martin et al., 1996). As noted above, $\alpha$-bungarotoxin labeled AChRs in the postsynaptic membrane. Two antibodies stained cytoskeletal proteins concentrated beneath the postsynaptic membrane: rapsyn and utrophin (Hall and Sanes, 1993). In all cases, the distribution and approximate levels of antigen in mutant were indistinguishable from wild type (Fig. 3 and data not shown). Thus, we detected no significant effect of $\mathrm{N}-\mathrm{CAM}$ on the molecular architecture of the NMJ in adult mice.

\section{Development}

Although the microscopic and molecular structure of adult NMJs was not detectably affected by the absence of N-CAM, it seemed 

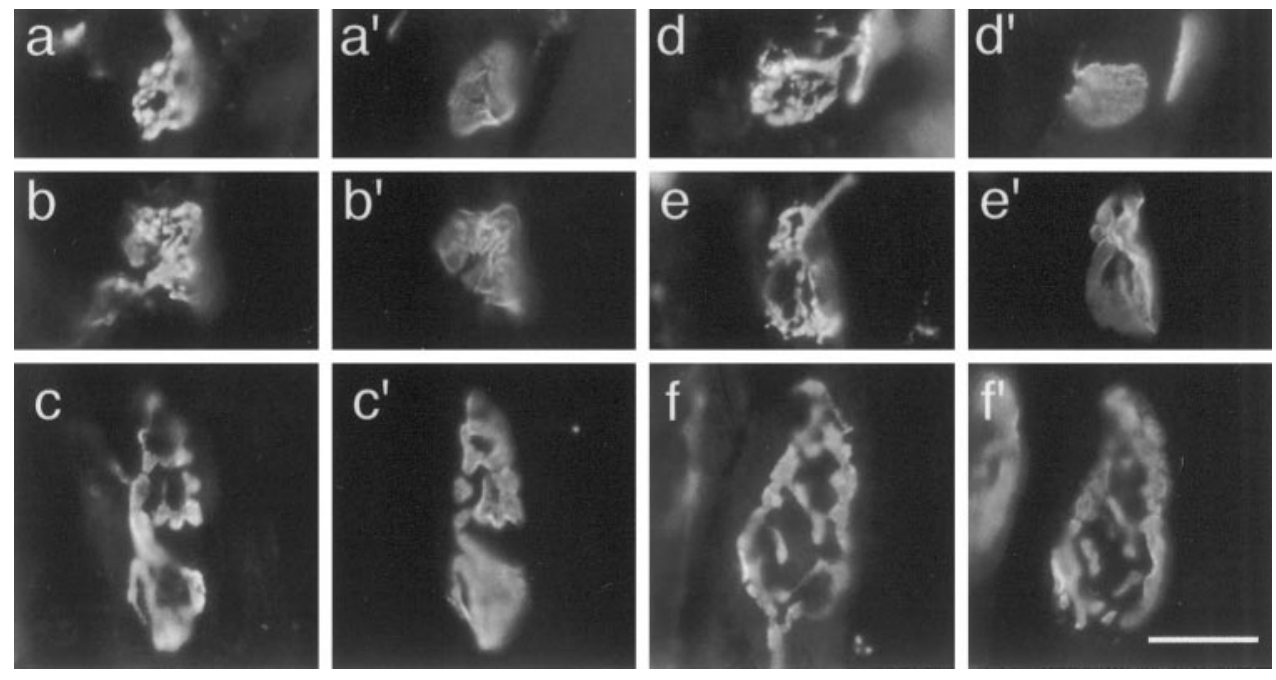

Figure 4. Postnatal maturation of the NMJ in control $(a-c)$ and N-CAM ${ }^{-1-}$ $(d-f)$ mice. Longitudinal sections of sternomastoid muscles from $\mathrm{P} 0(a, d), \mathrm{P} 7(b, e)$, and P14 $(c, f)$ mice were stained as in Figure 1, with antibodies to neural antigens $(a-f)$ plus rhodamine $-\alpha$-bungarotoxin $\left(a^{\prime}-\right.$ $\left.f^{\prime}\right)$. In both mutants and controls, initial plaque-like endings are remodeled to form branched end plates during the first 2 postnatal weeks. Scale bar, $20 \mu \mathrm{m}$. possible that development would be delayed or perturbed in the mutant. To assess this possibility, we examined synapses during the first 2 postnatal weeks. NMJs are functional at birth, but they mature in at least four respects during this early postnatal period. First, synaptic geometry becomes more complex as the nerve terminal elaborates fine branches within the end plate region, and the AChR-rich postsynaptic domain is transformed from a plaque with poorly defined boundaries to a highly branched "pretzel" with well defined boundaries (Steinbach, 1981; Slater, 1982). Second, end plates are multiply innervated at birth and become singly innervated as a result of synapse elimination (Colman and Lichtman, 1993). Third, molecular distinctions between synaptic and extrasynaptic regions of the muscle fiber surface become greater; some synaptic antigens do not become detectable until postnatally, and some that are initially expressed throughout the myofiber become concentrated at synapses postnatally (see below). Finally, the junctional folds that invaginate the postsynaptic membrane form after birth (Matthews-Bellinger and Salpeter, 1983).

To determine whether any of these developmental events were $\mathrm{N}-\mathrm{CAM}$-dependent, we first studied the geometrical changes that occur in presynaptic and postsynaptic structures. In wild-type mice, the nerve terminal is poorly branched and overlies ovoid plaques of AChRs with poorly defined borders (Fig. 4a, $a^{\prime}$ ). Gradually, AChR-poor "holes" appear within the plaques, and the nerve terminals elaborate finer branches (Fig. $4 b, b^{\prime}$ ). Finally the branching pattern of the nerve terminal becomes more distinct and overlaps a correspondingly branched AChR-rich region with distinct boundaries (Fig. 4c, $c^{\prime}$ ). A similar progression was seen in mutant mice (Fig. $4 d-f$ ).

Next, we evaluated synapse elimination by counting the number of motor axons that entered each AChR-rich end plate. At postnatal day $0(\mathrm{P} 0), 50$ and $59 \%$ of muscle fibers were singly innervated in wild-type and mutant sternomastoid, respectively. By P14, all end plates in a wild-type muscle but only $84 \%$ of end plates in mutant muscle were singly innervated. All end plates were singly innervated in adult mutant muscle. Our control values are similar to those reported previously for wild-type sternomastoid by Balice-Gordon and Lichtman (1993). Thus, synapse elimination appears to be slightly delayed in the mutant, but it occurs within several days of the normal schedule.

Third, we stained muscles to reveal four components that become confined to the postsynaptic membrane postnatally: agrin, neuregulin, $N$-acetylgalactosaminyl-terminated carbohydrates (recognized by the lectin VVA-B4), and integrin $\alpha 7 \mathrm{~A}$. Agrin, neuregulin, and $N$-acetylgalactosaminyl-terminated carbohydrates are present throughout the myofiber membrane at birth, but expression becomes restricted to the postsynaptic surface by P14 (Hoch et al., 1993; Moscoso et al., 1995) (P. T. Martin and J. R. Sanes, unpublished observation). Integrin $\alpha 7 \mathrm{~A}$ is undetectable at birth and appears specifically at the synapse during the first postnatal week (Martin et al., 1996). The distribution of each of these components was indistinguishable in wild-type and mutant muscles examined at P0, P7, and P14 (data not shown). Thus the synaptic localization of these molecules occurs via an N-CAM-independent mechanism.

Finally, we used electron microscopy to assess the ultrastructure of the developing NMJ. No qualitative differences were seen between the mutant and wild-type nerve terminals at P7 or P15; synaptic vesicles filled the nerve terminal, Schwann cell processes capped each terminal, and junctional folds invaginated the postsynaptic membrane. However, we were struck by a relative paucity of folds in mutant end plates (Fig. $5 a, b$ ). We had shown previously that N-CAM is localized at the depths of the folds in the adult, and we hypothesized that N-CAM plays a role in the formation or maintenance of folds (Covault and Sanes, 1986). We therefore counted the number of folds in 45 synaptic profiles from two mutant mice and 72 synaptic profiles from three control mice at P7. There were approximately threefold more folds per profile in control mice ( 2.26 folds per profile) than in the mutant ( 0.82 folds per profile). This difference was statistically significant $(p<0.001)$ and did not merely reflect delayed overall growth of mutant end plates, because the difference persisted when values were normalized to the size of the junction (Fig. 5c). The difference was transient, however; it was statistically insignificant $(p>0.2)$ by $\mathrm{P} 15$ and absent in the adult (Fig. $5 c$ ). Thus, formation of junctional folds is delayed, but not prevented, in $\mathrm{N}^{-\mathrm{CAM}^{-/-}}$mice.

\section{Reinnervation}

As noted above, N-CAM is regulated in parallel with muscle susceptibility to innervation (references in introductory remarks). Based on this correlation, it was suggested that N-CAM on denervated muscle fibers promotes reinnervation, perhaps by interacting with N-CAM on the motor axon. Consistent with this possibility, antibodies to N-CAM delay reinnervation in frogs and mice (Rieger et al., 1988; Langenfeld-Oster et al., 1994). To test 


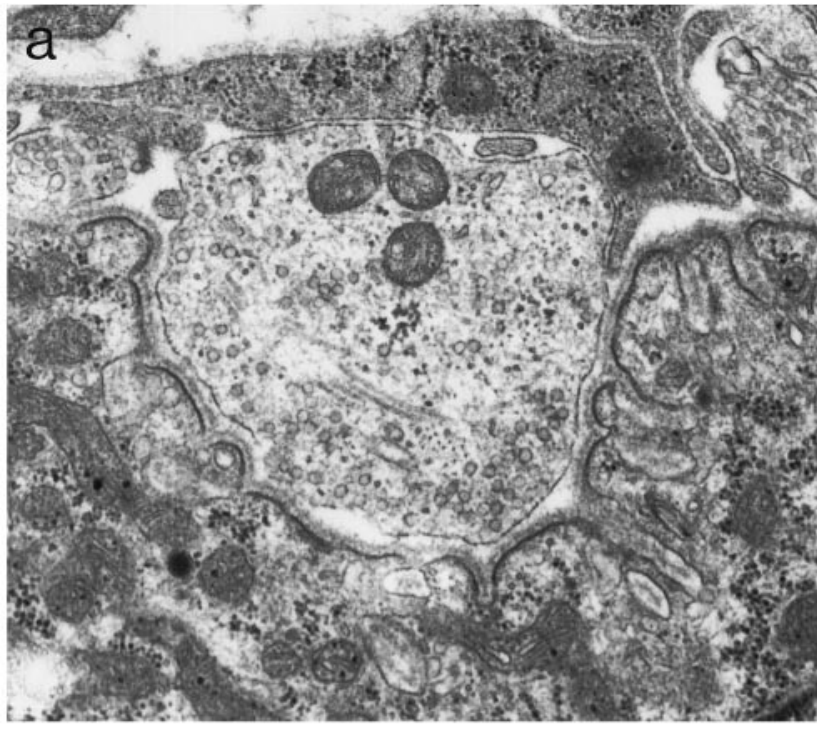

C

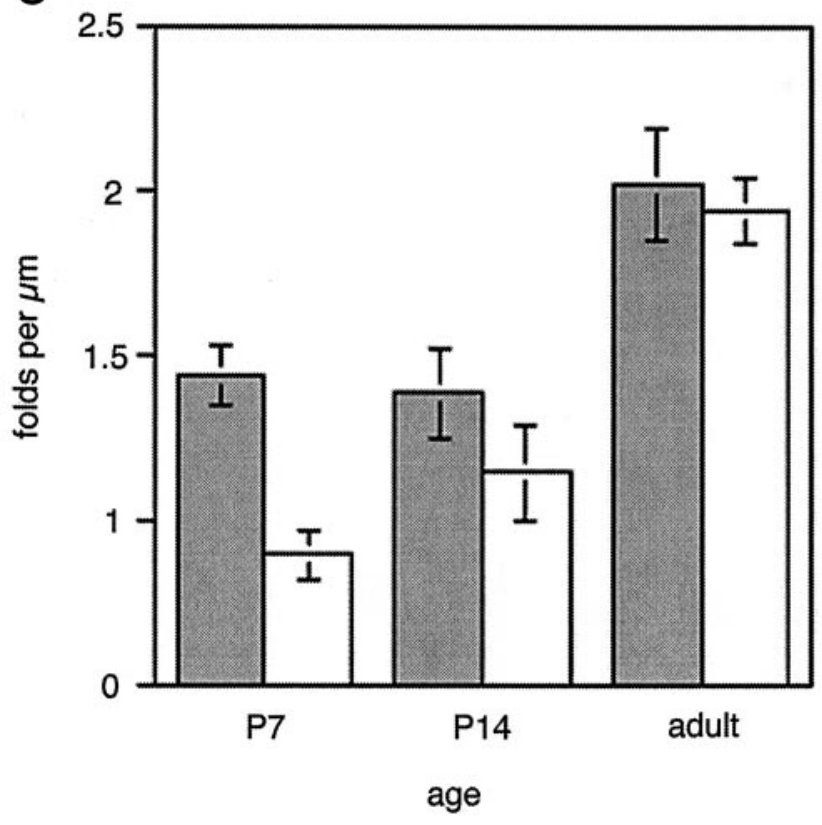

this hypothesis further, we assayed reinnervation of sternomastoid muscles in $\mathrm{N}-\mathrm{CAM}^{-/-}$mice. Muscles were sectioned and doubly stained for nerve terminals and AChRs 3-7 d after nerve crush. It is known that AChR aggregates persist for months after denervation, and that regenerating axons exclusively reinnervate original synaptic sites under these conditions (Rich and Lichtman, 1989). Therefore, the extent to which AChR-rich membranes are reoccupied by axons provides a reliable measure of reinnervation. Using this measure, we found that end plates in both control and mutant muscles were nearly completely reinnervated by 1 week after nerve crush (Fig. 6a,b). Moreover, the precise apposition of presynaptic and postsynaptic sites indicated that original synaptic sites were as selectively reinnervated in mutant as in wild-type mice. Quantitation of the fraction of synaptic sites reoccupied between 3 and $7 \mathrm{~d}$ after nerve crush indicated that the rate of reinnervation was similar in mutants and controls (Fig. $6 c$ ).

Much of the time between axotomy and the initiation of rein-

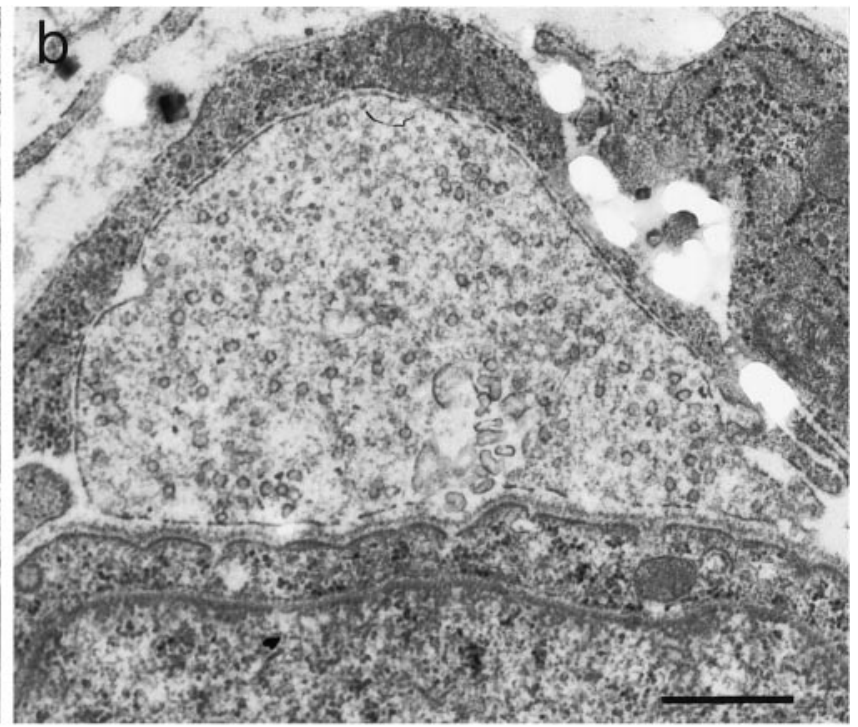

Figure 5. Formation of junctional folds is delayed in the absence of N-CAM. $a, b$, Electron micrographs of NMJs from wild-type $(a)$ and $\mathrm{N}-C A M^{-1-}(b)$ mice at P7. $c$, Number of postsynaptic folds per micrometer of nerve-muscle apposition, counted from electron micrographs such as those in $a$ and $b$. Each point represents the mean \pm SEM measurements from 20-72 end plates in two or three mice. Indentations of the postsynaptic membrane $>50 \mathrm{~nm}$ deep were counted as folds. Scale bar, $0.5 \mu \mathrm{m}$.

nervation involves regeneration of axons from the point of injury to the myofiber surface. If this time was unaffected by N-CAM, it is possible that our measurements would have been insensitive to a delay in synapse formation per se. To test this idea, we asked whether the fraction of postsynaptic surface covered by regenerating axons differed between mutant and wild-type mice at a time when many end plates had been reached just recently. The reinnervation of single end plates was quantified by estimating the amount of end plate region covered by nerve terminal. This distribution was similar in three pairs of control and mutant animals (Fig. 6d). These results showed that the rate at which axons reoccupied end plates was not detectably N-CAM-dependent.

\section{Schwann cells}

Recent studies have shown that terminal Schwann cells elaborate processes after denervation of rat muscle (Reynolds and Woolf, 1992), and that reinnervating axons follow these processes (Son 

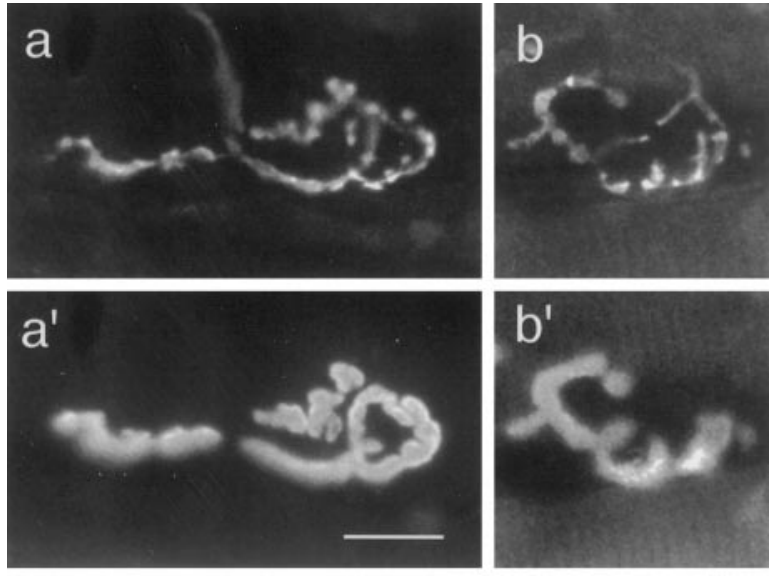

C

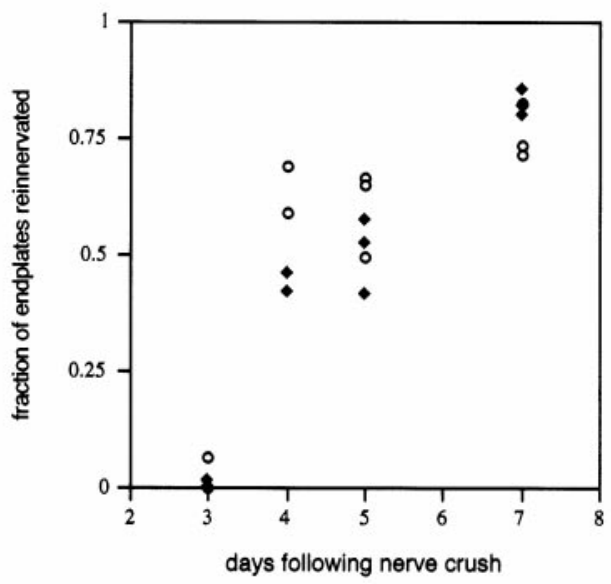

d

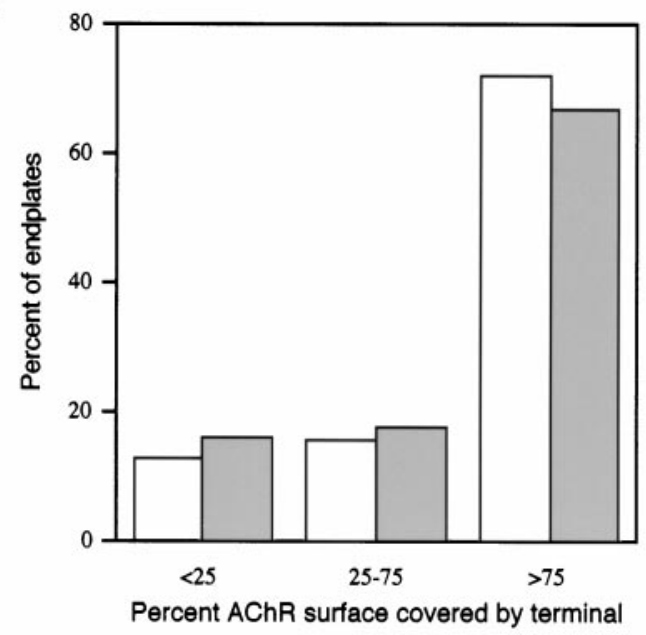

Figure 6. Reinnervation of denervated end plates occurs at a normal rate in N-CAM mutant mice. $a$, $b$, Longitudinal sections of $7 \mathrm{~d}$ reinnervated sternomastoid muscles from control $(a)$ and $\mathrm{N}_{-} \mathrm{CAM}^{-1-}(b)$ mice were stained as in Figure 1. The nerve terminal $(a, b)$ reoccupies AChR-rich original synaptic sites $\left(a^{\prime}, b^{\prime}\right)$ during reinnervation. $c$, Fraction of end plates reinnervated at various times after nerve crush in mutant ( filled diamonds) and control (open circles) animals. Each point represents an average of 116 end plates from a single animal. $d$, Fraction of AChR-rich postsynaptic membrane covered by nerve terminal for three pairs of mutant (shaded) and control (open) mice at 5-7 d after nerve crush. In $c$, end plates were counted as reinnervated if any portion of the AChR-rich postsynaptic membrane was apposed by a nerve terminal. In $d$, only reinnervated end plates were scored. Scale bar, $20 \mu \mathrm{m}$. and Thompson, 1995). Because Schwann cells as well as motoneurons and muscle fibers express N-CAM, it seemed possible that interactions of Schwann cells with nerve, muscle, or both would be affected by N-CAM. For example, Schwann cells might have been unable to sense the loss of the nerve on denervation or to interact properly with denervated muscle. To test this possibility, we stained denervated muscles with antibodies to the Schwann cell-specific marker S-100. Schwann cells formed processes after denervation of mouse muscle (Fig. $7 a, b)$ as reported previously for rat. Similar numbers of terminal Schwann cells formed processes in mutant and control muscles [sprouts at 94 of 101 end plates $(93 \%)$ in two mutant animals and at 55 of $70(79 \%)$ in two controls]. Moreover, the length of processes did not differ significantly between wild-type and mutant mice (Fig. 7c). Thus, $\mathrm{N}-\mathrm{CAM}$ is not required for Schwann cell sprouting after denervation.

In studying muscles treated with anti-N-CAM, Rieger et al. (1988) found that Schwann cells often failed to cap nerve terminals after reinnervation. To see whether N-CAM plays a role in the adhesion of the terminal Schwann cell to the nerve terminal, we assessed the ultrastructure of reinnervated end plates with electron microscopy in two mutant and two control sternomastoid muscles. Nerve terminals were capped by Schwann cell processes at all reinnervated end plates in both mutants and controls (data not shown). Thus, N-CAM is not essential for Schwann cell processes to cap reinnervating nerve terminals.

\section{Sprouting}

After nerve crush, most axons regenerate through Schwann cell tubes in intramuscular nerves and are thereby guided to original synaptic sites (for review, see Sanes and Covault, 1985). Consequently, some ingrowing axons may not interact with extrasynaptic portions of the muscle membrane. In contrast, nerve terminals sprout beyond the boundaries of the end plate in partially denervated or paralyzed muscle, in which case they do interact with extrasynaptic regions (Hoffman, 1950; Brown et al., 1981). Because denervation and inactivity lead to appearance of N-CAM in extrasynaptic membrane, it was suggested that N-CAM promotes such sprouting (Covault and Sanes, 1985). In support of this idea, anti-N-CAM partially inhibits growth of motor axons on myotubes in vitro (Bixby et al., 1987) and partially inhibits sprouting after paralysis in vivo (Booth et al., 1990). Accordingly, we asked whether motor axons were capable of terminal sprouting in mutant mice. To this end, we partially denervated the sternomastoid muscle (see Materials and Methods), waited $7 \mathrm{~d}$ for sprouts to form, and then doubly stained sections to reveal axons and AChRs. Seven days after partial denervation, innervated end plates had elaborated sprouts in both control and $\mathrm{N}-\mathrm{CAM}^{-/-}$ muscles. Consistent with previous descriptions, sprouts in controls were thinner than nerve terminals and bore occasional swellings along their length (Fig. 8a). In $\mathrm{N}^{-C_{A M}}{ }^{-1-}$ mice, sprouts were also present and had similar morphology (Fig. 8b). Moreover, nerve terminal sprouting occurred in the mutant to the same extent as in the control; terminal sprouts were present at $36 \%$ of innervated end plates in mutants (18 of 51 in three muscles) and at $37.5 \%$ in controls (38 of 91 in four muscles). These results show that N-CAM is dispensable for terminal sprouting.

\section{Tenascin-C mutants}

Like the N-CAM ${ }^{-/-}$mutants, tenascin-C-mutant mice are externally normal (Saga et al., 1992; Forsberg et al., 1996), but previous 

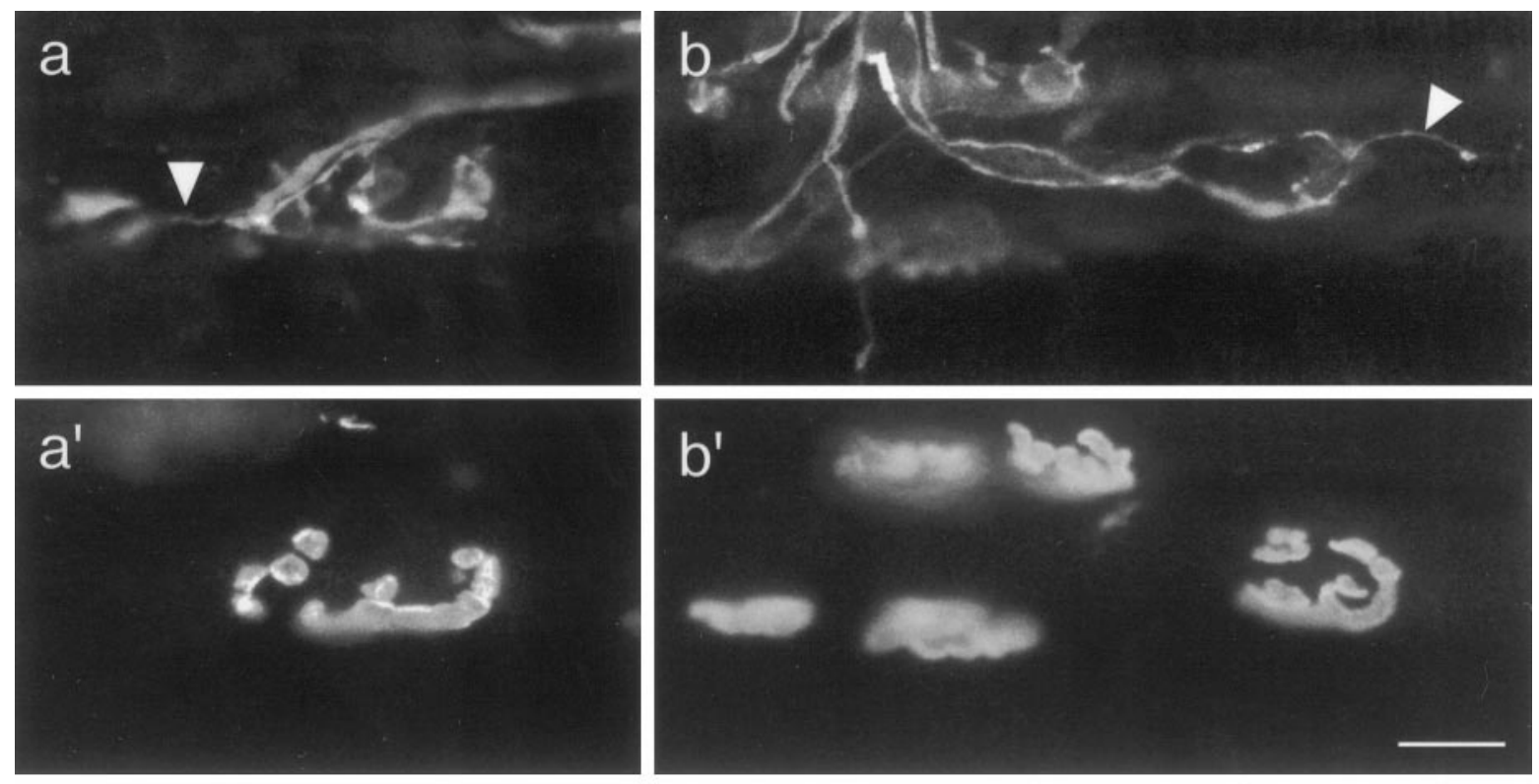

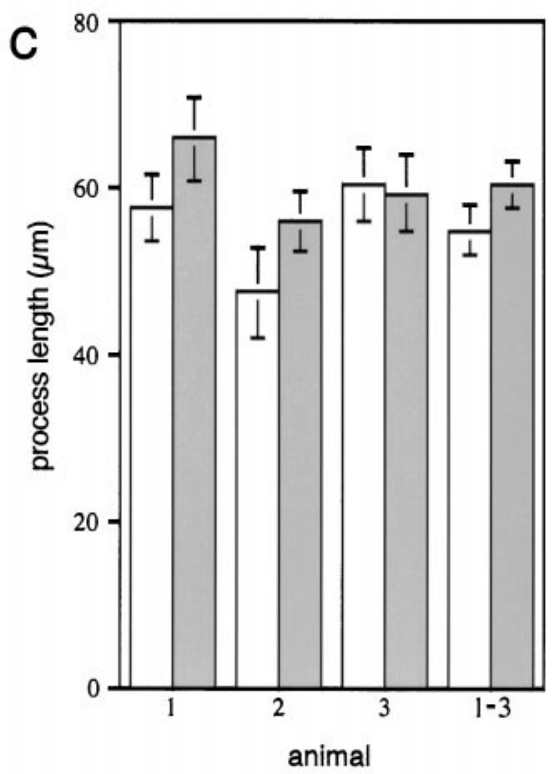

Figure 7. Terminal Schwann cells extend processes in denervated $\mathrm{N}-\mathrm{CAM}^{-1-}$ muscle. $a$, $b$, Longitudinal sections of $7 \mathrm{~d}$ denervated muscle from control $(a)$ and $\mathrm{N}^{-\mathrm{CAM}^{-1}}(b)$ mice were stained with anti-S-100 $(a, b)$ and rhodamine- $\alpha$-bungarotoxin $\left(a^{\prime}, b^{\prime}\right)$. In both controls and mutants, terminal Schwann cells extend processes (arrowheads) after double nerve crush. $c$, Extension of Schwann cell processes beyond the AChR-rich postsynaptic membrane, measured from micrographs such as those in $a$ and $b$. Schwann cell sprouts [130 in 3 control mice (open bars) and 138 in 3 mutant mice (hatched bars)] were measured. The first six bars represent single animals (mean \pm SEM). All data are combined in the last pair of bars. Scale bar, $20 \mu \mathrm{m}$. studies of their neuromuscular system have not been reported. We therefore examined synapses in adult mutant mice but found no significant difference between tenascin- $\mathrm{C}^{-1-}$ mice and controls (Fig. 9; data not shown). Because the protocols were identical to those described above, the results can be summarized briefly: (1) staining with rhodamine- $\alpha$-bungarotoxin plus antibodies to neural antigens showed that end plates were normal in size and shape in tenascin- $\mathrm{C}^{-1-}$ mutants (Fig. $9 a$ ); (2) electron microscopy revealed normal ultrastructure of nerve terminals, Schwann cells, and muscle fibers at mutant NMJs (data not shown); (3) all synaptic antigens tested (synaptophysin, SV2, neuregulin, N-CAM, laminin $\beta 2$, erbB2, erbB3, agrin, rapsyn, and integrin $\alpha 7 \mathrm{~A}$ ) were localized identically in mutants and controls (data not shown); (4) intact mutant nerve terminals formed sprouts within $7 \mathrm{~d}$ of partial denervation; the sprouts in the mutant were similar in morphology to those of controls (Fig. 9b), and the extent of sprouting was similar in mutant and control muscles $(37.5 \%$ of 91 end plates in four control muscles and
$50.5 \%$ of 128 end plates in four mutant muscles); and (5) $>80 \%$ of end plates in the sternomastoid were reinnervated $7 \mathrm{~d}$ after nerve crush (Fig. 9c). Moreover, in mutant as in control animals, axons reoccupied original synaptic sites precisely, although, as in controls, some original sites were only partially reoccupied (data not shown). Together, these data show that NMJs can form and regenerate in the absence of tenascin-C.

\section{FGF-5 mutants}

Hébert et al. (1994) generated mutant mice with a null allele of the FGF-5 gene. Although FGF-5 is expressed in numerous embryonic and adult tissues, the only phenotype detected in mutant homozygotes was a marked increase in hair length. Analysis of the mutants indicated that FGF-5 is an inhibitor of hair elongation and revealed that a previously identified and commercially available spontaneous mutant, angora ( $g o$ ), was another null allele of FGF-5 (Hébert et al., 1994). In light of suggestions that FGF-5 might be a muscle-derived regulator of motor axons (see 

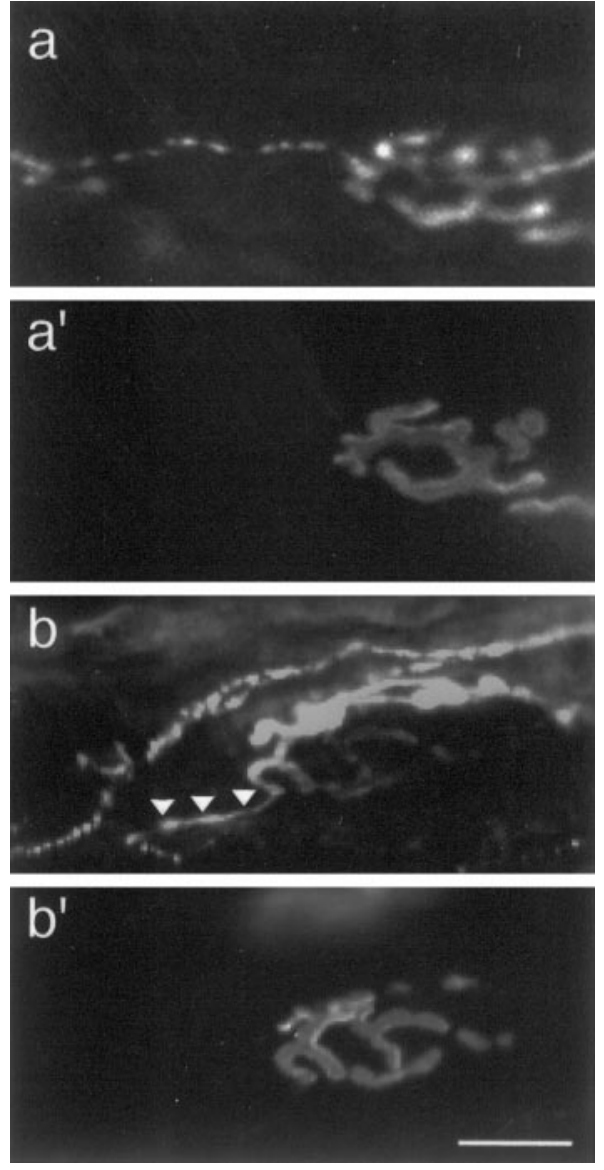

Figure 8. Intact motor nerve terminals sprout after partial denervation of N-CAM-deficient muscles. Sternomastoid muscles were sectioned longitudinally $7 \mathrm{~d}$ after partial denervation, and sections were stained as in Figure 1 , with antibodies to neural antigens $(a, b)$ and rhodamine- $\alpha$ bungarotoxin $\left(a^{\prime}, b^{\prime}\right)$. Intact end plates in both control $(a)$ and $\mathrm{N}-C A M^{-1-}(b)$ muscle extended terminal sprouts. Arrowheads in $b$ point to terminal sprout. Scale bar, $20 \mu \mathrm{m}$.

introductory remarks), we examined neuromuscular junctions in adult go homozygotes. As for the N-CAM and tenascin-C mutants described above, synaptic geometry was normal in FGF-5 mutants (Figure 10a, $a^{\prime}$ ). Further immunochemical characterization of cross-sectioned material failed to reveal any abnormalities of the motor nerve terminal (synaptophysin and SV2) terminal Schwann cell (S-100), synaptic basal lamina (neuregulin, laminin $\beta 2$, and agrin), or postsynaptic membrane (N-CAM, erbB3, integrin $\alpha 7 \mathrm{~A}$, and AChRs; data not shown).

Because soluble factors have been repeatedly implicated as promoters of sprouting (Brown et al., 1981; Hall and Sanes, 1993), we also partially denervated sternomastoid muscles in two go mice and then counted sprouts $7 \mathrm{~d}$ later (Fig. 10b, $b^{\prime}$ ). Approximately half of the intact nerve terminals extended sprouts in the mutant muscles (40 and 58\% in the two animals), a frequency similar to that observed in the control $(37.5 \%), \mathrm{N}-C A M^{-1-}$ $(36 \%)$, and tenascin- $\mathrm{C}^{-1-}(50.5 \%)$ muscles described above.

\section{An N-CAM/tenascin-C double mutant}

One explanation for unexpectedly subtle phenotypes of null mutants is that the mutated gene was only one of two or more capable of performing the function in question. When this is the case, double mutants lacking both genes often have far more
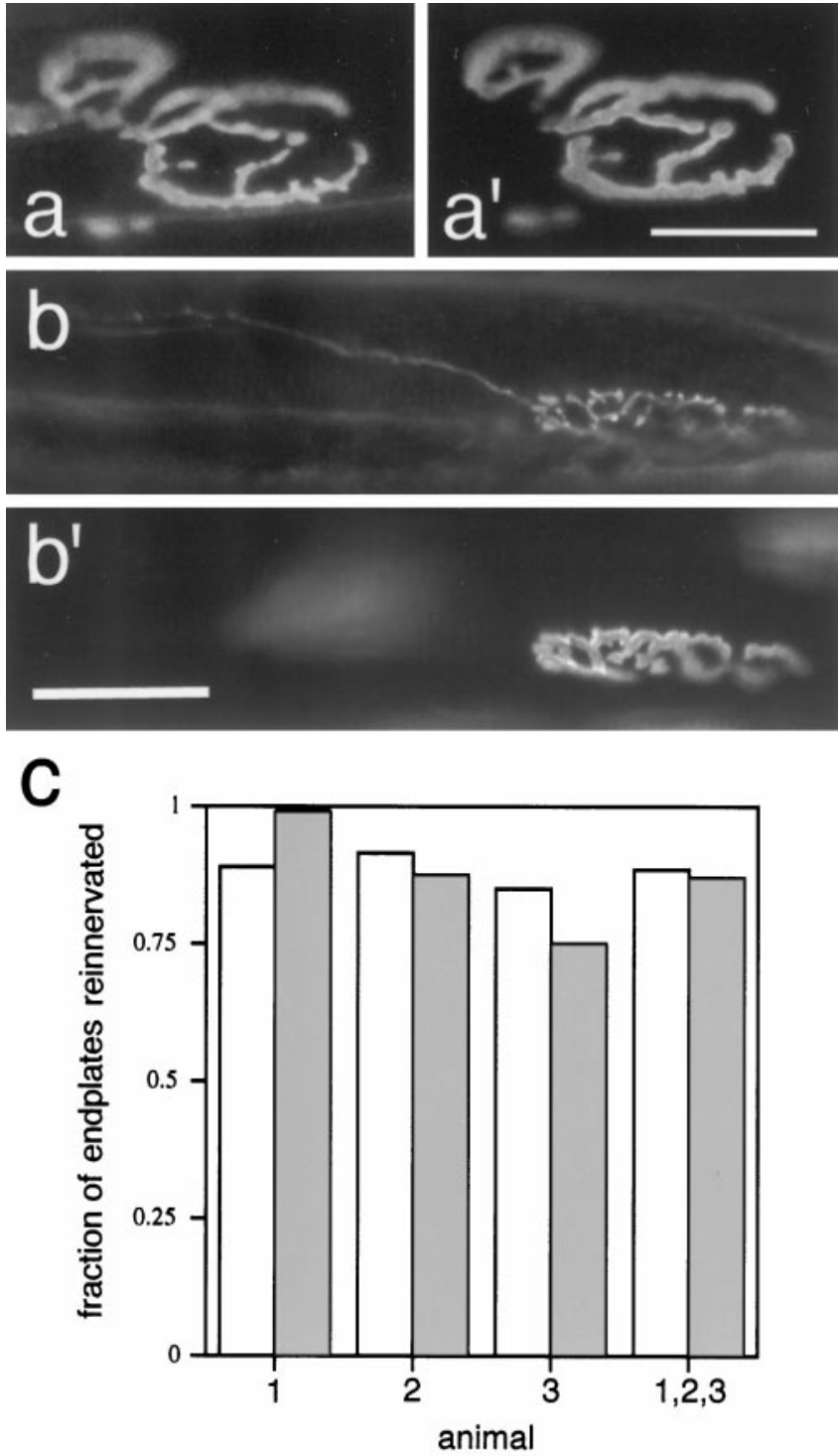

Figure 9. NMJs of mice lacking tenascin-C. $a, b$, NMJs from adult tenascin- $\mathrm{C}^{-1-}$ sternomastoid muscles, stained for nerve $(a, b)$ and AChRs $\left(a^{\prime}, b^{\prime}\right)$ as in Figure 1. $a$, The mutant NMJ is indistinguishable from controls (compare with Fig. 1a). $b$, Terminal sprouting from an intact end plate in a tenascin- $\mathrm{C}^{-1-}$ muscle $7 \mathrm{~d}$ after partial denervation. The sprouts resemble those seen in controls (compare with Fig. $8 a$ ). $c$, Fraction of end plates reinnervated $7 \mathrm{~d}$ after nerve crush in tenascin- $\mathrm{C}^{-1-}$ (shaded) and control (open) muscle. Each bar represents 48-185 end plates from a single animal. The first three pairs of bars represent age-matched pairs of animals. All data are combined in the last pair of bars. Scale bar, $20 \mu \mathrm{m}$.

severe phenotypes than either single mutant (see Discussion). As a first step in evaluating this possibility, we mated tenascin- $\mathrm{C}^{-/-}$ and $\mathrm{N}-\mathrm{CAM}^{-1-}$ mice to produce compound heterozygotes $(\mathrm{N}$ $\mathrm{CAM}^{+/-}$and tenascin- $\left.\mathrm{C}^{+/-}\right)$and then mated these to generate mice doubly homozygous for the N-CAM and tenascin-C null mutations. This combination was chosen because antibodies to $\mathrm{N}-\mathrm{CAM}$ and tenascin-C have similar (although not identical) effects on reinnervation (Rieger et al., 1988; Mège et al., 1992; Langenfeld-Oster et al., 1994). Several litters of offspring, totaling $\sim 100$ pups, were genotyped by PCR shortly after weaning. We expected to find approximately six double mutants $(1 / 4 \times 1 / 4 \times$ $100)$ in this cohort but found only one. This low number might reflect a statistical anomaly, increased mortality of the double 

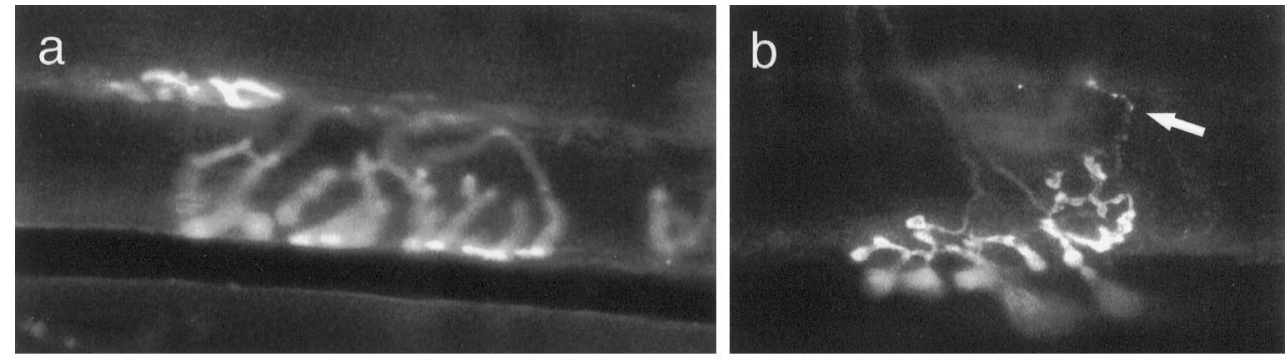

Figure 10. NMJs in sternomastoid muscles of adult mice lacking FGF-5 stained for nerve $(a, b)$ and AChRs $\left(a^{\prime}, b^{\prime}\right)$ as in Figure 1. $a$, The mutant NMJ is indistinguishable from controls (compare with Fig. 1a). $b$, Terminal sprouting from an intact end plate in an FGF-5 $5^{-1-}$ muscle $7 \mathrm{~d}$ after partial denervation. The sprout (arrow) resembles those seen in controls (compare with Fig. 8a). Scale bar, $20 \mu \mathrm{m}$.
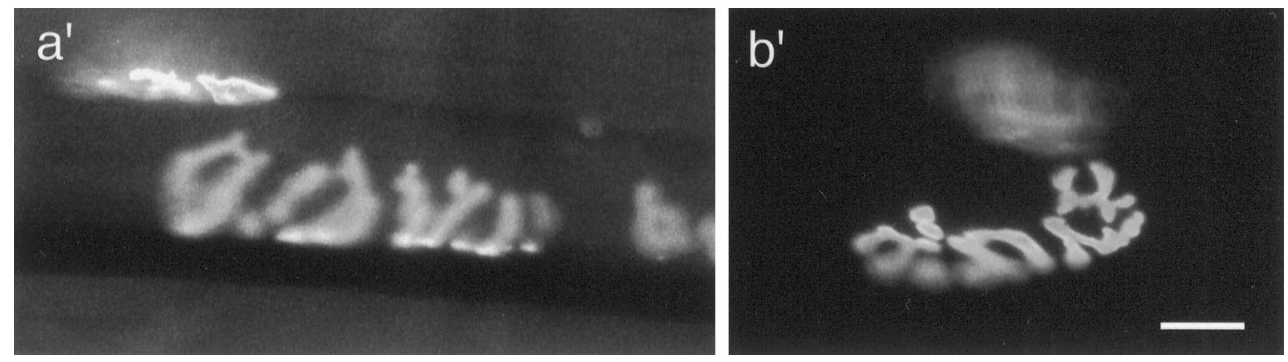

mutant (either embryonically or postnatally), or the fact that a subset of animals was discarded because we were unable to genotype them definitively for technical reasons. Nonetheless, the only double mutant was studied in some detail.

In a single operation, one sternomastoid muscle was completely denervated, and the contralateral sternomastoid was partially denervated. As before, complete denervation was performed by crushing the nerve, whereas partial denervation was done by severing a portion of the nerve. The crushed axons regenerated rapidly, whereas reinnervation by cut axons was delayed, permitting assessment of sprouting by the remaining intact axons. Seven days after surgery, the animal was killed, and the double-staining protocol was used to reveal nerve terminals and AChRs in both sternomastoids and several leg muscles. We detected no differences between double mutant and control NMJs (Fig. 11a, compare with Fig. 1a). Original synaptic sites were reinnervated in the muscle that had been completely denervated (Fig. 11b, compare with Fig. $6 a$ ). Intact terminals had formed sprouts in the partially denervated muscle, and the sprouts were similar in shape to those observed in the single mutants and in controls (Fig. 11c, compare with Fig. 8). Moreover, the extent of reinnervation and terminal sprouting was not lower in the double mutant than in controls or single mutants; all of the denervated end plates (40 of 40) had been reinnervated, and 29 of $43(67 \%)$ intact end plates in the partially denervated muscle bore terminal sprouts. From these data, we conclude that N-CAM and tenascin-C are not functionally redundant in terms of molecular architecture, reinnervation, and sprouting.

\section{DISCUSSION}

There is abundant evidence that muscles regulate the behavior of motor axons as NMJs form in embryos, mature postnatally, are maintained in adulthood, and regenerate after injury (Hall and Sanes, 1993). Numerous molecules have been suggested as retrograde mediators of these interactions, based on three types of evidence: (1) they are expressed at relatively high levels in embryonic and/or denervated muscles, which are most susceptible to innervation; (2) when presented to motoneurons in vitro, the purified proteins promote survival, growth, adhesion, neurite extension or differentiation; and (3) administration of exogenous molecules or antisera to them perturbs neuromuscular interactions in vivo. As detailed in the introductory remarks, all three lines of evidence have supported the candidacy of N-CAM, tenascin-C, and FGF-5 as regulators of synaptogenesis at the vertebrate NMJ.

In studies reported here, we attempted to define roles of N-CAM, tenascin-C, and FGF-5 further by documenting abnormalities in the structure, molecular architecture, development, or regeneration of NMJs in mutant mice lacking each of these three proteins and in a single mouse lacking both N-CAM and tenascin-C. Surprisingly, the only abnormalities we detected were a delay in the formation of junctional folds, a possible slowing of synapse elimination, and a slight decrease in end plate size in N-CAM mutant mice. Three potential explanations for the apparent discrepancies between these and previous results are that (1) we failed to detect some neuromuscular defects; (2) other, related molecules may have been able to compensate for loss of the mutated gene products; and (3) some previous perturbation studies may have given misleading results. We shall consider the first two of these possibilities.

Clearly, our search for neuromuscular defects in these mice was not exhaustive. Although we probably would have detected major changes in the geometry or molecular architecture of the synapse, modest changes in antigen levels would have gone undetected. In mutants lacking the synaptic cytoskeletal component utrophin, for example, AChR density is decreased significantly but the difference was not striking visually (Deconinck et al., 1997a; Grady et al., 1997a). Likewise, although we failed to detect differences after complete or partial denervation, the proteins could play roles in other stressful situations in murine life that we did not test, such as muscle damage, exercise or aging. In addition, tenascin- $\mathrm{C}^{-/-}$and $\mathrm{FGF}-5^{-/-}$mutants were studied in less detail than $\mathrm{N}-\mathrm{CAM}^{-/-}$mice, so subtle defects were more likely to have been overlooked. Perhaps most important, we did not study some phenomena relevant to neuromuscular development in which the molecules have been implicated. For example, N-CAM has been proposed to be required for some aspects of peripheral nerve guidance (Landmesser et al., 1988; Tang et al., 1993) and myogenesis (Fredette et al., 1993; Fazeli et al., 1996), tenascin-C may contribute to the stability of myotendinous junctions or muscle spindles (Chiquet and Fambrough, 1984; Pedrosa-Domellof et al., 1995), and FGF-5 may be required for survival of some motoneu- 

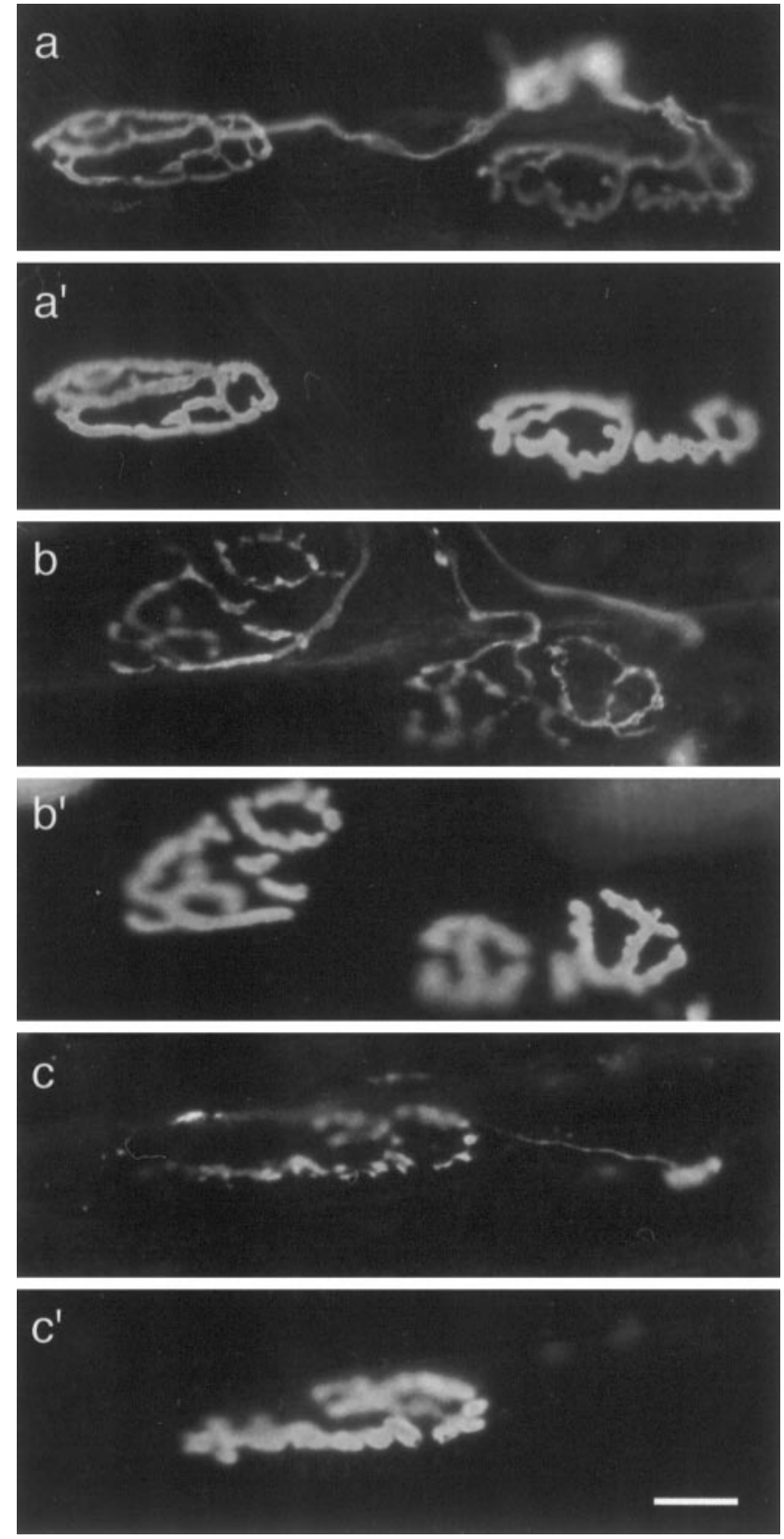

Figure 11. NMJs from a mouse lacking both N-CAM and tenascin-C. Muscles from a doubly mutant animal were sectioned longitudinally and stained for nerves $(a-c)$ and AChRs $\left(a^{\prime}-c^{\prime}\right)$, as in Figure 1. $a$, The nerve terminals and AChRs of an adult NMJ are indistinguishable from those in controls (compare with Fig. 1). $b$, Original synaptic sites are completely reoccupied by regenerated axons $7 \mathrm{~d}$ after nerve crush. $c$, Seven day partially denervated muscles elaborate terminal sprouts from innervated end plates. Scale bar, $20 \mu \mathrm{m}$.

rons (Hughes et al., 1993a). Further studies would be needed to test these possibilities.

Another general explanation for unexpectedly subtle phenotypes of null mutants is that the mutated gene is only one of several that can perform the function in question. If two or more gene products are normally present and play similar roles, they are said to be redundant. Alternatively, loss of one gene may lead to enhanced expression or accumulation of another, which then compensates for lack of the first. Multiple examples of redundancy and compensation have been documented in nerves and muscles of mutant mice. For example, although forced expression of either myoD or myf5 can transform undifferentiated cells into muscle, myogenesis proceeds almost normally in mice carrying null mutations for either gene. In contrast, animals lacking both myoD and myf5 never form muscle (Rudnicki and Jaenisch, 1995). In this case, myoD and myf5 have functionally redundant roles in myogenesis. Similarly, loss of dystrophin from muscle leads to compensatory enhanced retention of its homolog, utrophin, attenuating the muscular dystrophy that would otherwise occur (Deconinck et al., 1997b; Grady et al., 1997b).

Because N-CAM, tenascin-C, and FGF-5 are all members of large multigene families, compensation and redundancy are plausible explanations for the lack of dramatic defects. With regard to $\mathrm{N}-\mathrm{CAM}$, numerous immunoglobulin superfamily molecules are expressed by motoneurons, myotubes, interstitial cells, or Schwann cells; these include thy-1, L1/Ng-CAM, TAG-1/axonin, and neurofascin (Booth et al., 1984; Moscoso and Sanes, 1995; Fazeli and Walsh, 1996). In the case of tenascin-C, the closely related homologs tenascin- $\mathrm{X}$ and -Y are both normally expressed in developing muscle and could play roles (Erickson, 1993; Burch et al., 1995; Chiquet-Ehrismann, 1995; Hagio et al., 1996). Likewise, at least five FGFs in addition to FGF-5 are expressed in developing or adult muscle or both, and most, if not all, of these are capable of interacting with the FGF receptors that motoneurons bear (Hannon et al., 1996; Ornitz et al., 1996).

We made two attempts to detect redundancy and compensation. First, we stained innervated and denervated muscles with antibodies to several immunoglobulin superfamily molecules (thy-1, L1/Ng-CAM, TAG-1/axonin-1, F3/F11/contactin, Nr$\mathrm{CAM} / \mathrm{BR} A V O$, and neurofascin) but detected no differences in their expression between wild-type and N-CAM-deficient mice (data not shown). Second, we examined innervation and reinnervation in an N-CAM/tenascin-C double mutant, based on previous results indicating that both N-CAM and tenascin-C interact with highly homologous members of the immunoglobulin superfamily (Brümmendorf and Rathjen, 1993; Chiquet-Ehrismann, 1995) and that antibodies to N-CAM and tenascin-C have similar effects on reinnervation (Rieger et al., 1988; Mège et al., 1992; Langenfeld-Oster et al., 1994). Again, no significant abnormalities were apparent in the single animal tested.

Despite these negative results, we favor the possibility that redundancy, compensation, or both may explain some differences between previous results and those reported here. Thus, function-blocking antibodies might be more effective at perturbing reinnervation than genetic ablation, because blockade occurs rapidly and may not provide sufficient opportunity for compensation to occur. Moreover, recent studies of fasciclin II, the Drosophila N-CAM ortholog, have demonstrated roles for this molecule in formation and plasticity of the fly NMJ (Schuster et al., 1996; Davis et al., 1997); perhaps the relative simplicity of the fly genome minimizes masking by redundancy or compensation. On the other hand, it is important to realize that most of the hypotheses about roles of N-CAM, tenascin-C, and FGF-5 in the vertebrate neuromuscular system were derived from analysis of expression patterns, from studies in vitro, and from pharmacological (overexpression) studies. A painful lesson of genetic studies in organisms from yeast to flies to mice is that these lines of indirect evidence are at best imperfect indicators of roles that molecules actually play in developmental processes in vivo. 


\section{REFERENCES}

Balice-Gordon RJ, Lichtman JW (1993) In vivo observations of pre- and post-synaptic changes during the transition from multiple to single innervation at developing neuromuscular junctions. J Neurosci 13:834-855.

Bixby JL, Reichardt LF (1987) Effects of antibodies to neural cell adhesion molecule (N-CAM) on the differentiation of neuromuscular contacts between ciliary ganglion neurons and myotubes in vitro. Dev Biol 119:363-372.

Bixby JL, Pratt RS, Lillien J, Reichardt LF (1987) Neurite outgrowth on muscle cell surfaces involves extracellular matrix receptors as well as $\mathrm{Ca}^{++}$-dependent and independent cell adhesion molecules. Proc Natl Acad Sci USA 84:2555-2559.

Booth CM, Brown MC, Keynes RJ, Barclay AN (1984) Muscles of adult rats and mice re-express the Thy-1 glycoprotein on denervation. Brain Res 308:380-382.

Booth CM, Kemplay SK, Brown MC (1990) An antibody to neural cell adhesion molecule impairs motor nerve terminal sprouting in a mouse muscle locally paralyzed with botulinum toxin. Neuroscience 35:85-91.

Brown MC, Holland RL, Hopkins WG (1981) Motor nerve sprouting. Annu Rev Neurosci 4:17-42.

Brümmendorf T, Rathjen FG (1993) Axonal glycoproteins with immunoglobulin- and fibronectin type III-related domains in vertebrates: structural features, binding activities, and signal transduction. J Neurochem 61:1207-1219.

Burch GH, Bedolli MA, McDonough S, Rosenthal SM, Bristow J (1995) Embryonic expression of tenascin-X suggests a role in limb, muscle, and heart development. Dev Dyn 203:491-504.

Calakos N, Scheller RH (1996) Synaptic vesicle biogenesis, docking, and fusion - a molecular description. Physiol Rev 76:1-29.

Chiquet M, Fambrough DM (1984) Chick myotendinous antigen. I. A monoclonal antibody as a marker for tendon and muscle morphogenesis. J Cell Biol 98:1926-1936.

Chiquet-Ehrismann R (1995) Tenascin-C, a growing family of extracellular matrix proteins. Experientia 51:853-862.

Colman H, Lichtman JW (1993) Interactions between nerve and muscle: synapse elimination at the developing neuromuscular junction. Dev Biol 156:1-10.

Covault J, Sanes JR (1985) Neural cell adhesion molecule (N-CAM) accumulates in denervated and paralyzed skeletal muscles. Proc Nat Acad Sci USA 82:4544-4548.

Covault J, Sanes JR (1986) Distribution of N-CAM in synaptic and extrasynaptic portions of developing and adult skeletal muscle. J Cell Biol 102:716-730.

Covault J, Merlie J, Goridis C, Sanes JR (1986) Molecular forms of $\mathrm{N}-\mathrm{CAM}$ and its RNA in developing and denervated skeletal muscle. J Cell Biol 102:731-739.

Cremer H, Lange R, Christoph A, Plomann M, Vopper G, Roes J, Brown R, Baldwin S, Kraemer P, Scheff S, Barthels D, Rajewsky K, Wille W (1994) Inactivation of the N-CAM gene in mice results in size reduction of the olfactory bulb and deficits in spatial learning. Nature 367:455-459.

Cremer H, Chazal G, Goridis C, Represa A (1997) NCAM is essential for axonal growth and fasciculation in the hippocampus. Mol Cell Neurosci 8:323-335.

Dai Z, Peng HB (1995) Presynaptic differentiation induced in cultured neurons by local application of basic fibroblast growth factor. J Neurosci 15:5466-5475.

Daniloff JK, Crossin KL, Pinçon-Raymond M, Murawsky M, Rieger R, Edelman GM (1989) Expression of cytotactin in the normal and regenerating neuromuscular system. J Cell Biol 108:625-635.

Davis GW, Schuster CM, Goodman CS (1997) Genetic analysis of the mechanisms controlling target selection: target-derived fasciclin II regulates the pattern of synapse formation. Neuron 19:561-573.

Deconinck AE, Potter AC, Tinsley JM, Wood SJ, Vater R, Young C, Metzinger L, Vincent A, Slater CR, Davies KE (1997a) Postsynaptic abnormalities at the neuromuscular junctions of utrophin-deficient mice. J Cell Biol 136:883-894.

Deconinck AE, Rafael JA, Skinner JA, Brown SC, Potter AC, Metzinger L, Watt DJ, Dickson JG, Tinsley JM, Davies KE (1997b) Utrophindystrophin-deficient mice as a model for Duchenne muscular dystrophy. Cell 90:717-727.

Erickson HP (1993) Tenascin-C, tenascin-R and tenascin-X: a family of talented proteins in search of functions. Curr Opin Cell Biol 5:869-876.
Fazeli S, Walsh FS (1996) The role of cell adhesion molecules during the development and regeneration of the neuromuscular system. Neuroscience 8:367-377.

Fazeli S, Wells DJ, Hobbs C, Walsh FS (1996) Altered secondary myogenesis in transgenic animals expressing the neural cell adhesion molecule under the control of a skeletal muscle alpha-actin promoter. J Cell Biol 135:241-251.

Forsberg E, Hirsch E, Fröhlich L, Meyer M, Ekblom P, Aszodi A, Werner S, Fässler R (1996) Skin wounds and severed nerves heal normally in mice lacking tenascin-C. Proc Natl Acad Sci USA 93:6594-6599.

Fredette B, Rutishauser U, Landmesser L (1993) Regulation and activity-dependence of N-cadherin, NCAM isoforms, and polysialic acid on chick myotubes during development. J Cell Biol 123:1867-1888.

Gatchalian CL, Schachner M, Sanes JR (1989) Fibroblasts that proliferate near denervated synaptic sites in skeletal muscle synthesize the adhesive molecules tenascin-C(J1), N-CAM, fibronectin, and a heparan sulfate proteoglycan. J Cell Biol 108:1873-1890.

Gautam M, Noakes PG, Moscoso L, Rupp F, Scheller RH, Merlie JP, Sanes JR (1996) Defective neuromuscular synaptogenesis in agrindeficient mutant mice. Cell 85:525-535.

Goridis C, Brunet J-F (1992) NCAM: structural diversity, function and regulation of expression. Semin Cell Biol 3:189-197.

Götz B, Scholze A, Clement A, Joester A, Schütte K, Wigger F, Frank R, Spies E, Ekblom P, Faissner A (1996) Tenascin-C contains distinct adhesive, anti-adhesive, and neurite outgrowth promoting sites for neurons. J Cell Biol 132:681-699.

Grady RM, Merlie JP, Sanes JR (1997a) Subtle neuromuscular defects in utrophin-deficient mice. J Cell Biol 136:871-882.

Grady RM, Teng H, Nichol MC, Cunningham JC, Wilkinson RS, Sanes JR (1997b) Skeletal and cardiac myopathies in mice lacking utrophin and dystrophin: a model for Duchenne muscular dystrophy. Cell 90:729-738.

Gurney ME, Yamamoto H (1991) Expression of recombinant rat ciliary neurotrophic factor in Escherichia coli and its synergy with basic fibroblast growth factor. Mol Cell Neurosci 2:369-376.

Gurney ME, Yamamoto H, Kwon Y (1992) Induction of motor neuron sprouting in vivo by ciliary neurotrophic factor and basic fibroblast growth factor. J Neurosci 12:3241-3247.

Hagio C, Koch M, Spring J, Chiquet M, Chiquet-Ehrismann R (1996) Tenascin-Y: a protein of novel domain structure is secreted by differentiated fibroblasts of muscle connective tissue. J Cell Biol 134:1499-1512.

Hall ZW, Sanes JR (1993) Synaptic structure and development: the neuromuscular junction. Cell/Neuron [Suppl] 72/10: 99-121.

Hannon K, Kudla AJ, McAvoy MJ, Clase KL, Olwin BB (1996) Differentially expressed fibroblast growth factors regulate skeletal muscle development through autocrine and paracrine mechanisms. J Cell Biol 132:1151-1159.

Hébert JM, Rosenquist T, Götz J, Martin GR (1994) FGF5 as a regulator of the hair growth cycle: evidence from targeted and spontaneous mutations. Cell 78:1017-1025.

Hoch W, Ferns M, Campanelli JT, Hall ZW, Scheller RH (1993) Developmental regulation of highly active alternatively spliced forms of agrin. Neuron 11:479-490.

Hoffman H (1950) Local reinnervation in partially denervated muscle: a histophysiological study. Aust J Exp Biol Med Sci 28:383-397.

Hughes RA, Sendtner M, Goldfarb M, Lindholm D, Thoenen H (1993a) Evidence that fibroblast growth factor 5 is a major muscle-derived survival factor for cultured spinal motoneurons. Neuron 10:369-377.

Hughes RA, Sendtner M, Thoenen H (1993b) Members of several gene families influence survival of rat motoneurons in vitro and in vivo. J Neurosci Res 36:663-671.

Ikeda K, Iwasaki Y, Tagaya N, Shiojima T, Kobayashi T, Kinoshita M (1995) Neuroprotective effect of basic fibroblast growth factor on wobbler mouse motor neuron disease. Neurol Res 17:445-448.

Karnovsky MJ, Roots L (1964) A "direct-coloring" thiocholine method for cholinesterases. J Histochem Cytochem 12:219-221.

Landmesser L, Dahm L, Schultz K, Rutishauser U (1988) Distinct roles for adhesion molecules during innervation of embryonic chick muscle. Dev Biol 130:645-670.

Langenfeld-Oster B, Faissner A, Irintchev A, Wernig A (1994) Polyclonal antibodies against NCAM and tenascin-C delay endplate reinnervation. J Neurocytol 23:591-604.

Li L, Oppenheim RW, Lei M, Houenou LJ (1994) Neurotrophic agents 
prevent motoneuron death following sciatic nerve section in the neonatal mouse. J Neurobiol 25:759-766.

Lindholm D, Hartikka J, da Penha Berzaghi M, Castrén E, Tzimagioris G, Hughes RA, Thoenen H (1994) Fibroblast growth factor-5 promotes differentiation of cultured rat septal cholinergic and raphe serotonergic neurons: comparison with the effects of neurotrophins. Eur J Neurosci 6:244-252.

Martin PT, Kaufman SJ, Kramer RH, Sanes JR (1996) Synaptic integrins in developing, adult, and mutant muscle: selective association of $\alpha 1, \alpha 7 \mathrm{~A}$, and $\alpha 7 \mathrm{~B}$ integrins with the neuromuscular junction. Dev Biol 174:125-139.

Martini R, Schachner M (1991) Complex expression pattern of tenascin-C during innervation of the posterior limb buds of the developing chicken. J Neurosci Res 28:261-279.

Matthews-Bellinger J, Salpeter MM (1983) Fine structural distribution of acetylcholine receptors at developing mouse neuromuscular junctions. J Neurosci 3:644-657.

Mège RM, Nicholet M, Pinçon-Raymond M, Murawsky M, Rieger F (1992) Cytotactin is involved in synaptogenesis during regeneration of the frog neuromuscular junction. Dev Biol 149:381-394.

Moore SE, Walsh FS (1985) Specific regulation of N-CAM/D2-CAM cell adhesion molecule during skeletal muscle development. EMBO J 4:623-630.

Moscoso LM, Sanes JR (1995) Expression of four immunoglobulin superfamily adhesion molecules (L1, NrCAM/Bravo, Neurofascin/ ABGP, and N-CAM) in the developing mouse spinal cord. J Comp Neurol 352:321-334.

Moscoso LM, Chu GC, Gautam M, Noakes PG, Merlie JP, Sanes JR (1995) Synapse-associated expression of an acetylcholine receptorinducing protein, ARIA/heregulin, and its putative receptors, ErbB2 and ErbB3, in developing mammalian muscle. Dev Biol 172:158-169.

Noakes PG, Gautam M, Mudd J, Sanes JR, Merlie JP (1995) Aberrant differentiation of neuromuscular junctions in mice lacking s-laminin/ laminin beta-2. Nature 374:258-262.

Olwin BB, Arthur K, Hannon K, Hein P, McFall A, Riley B, Szebenyi G, Zhou Z, Zuber ME, Rapraeger AC, Fallon JF, Kudla AJ (1994) Role of FGFs in skeletal muscle and limb development. Mol Reprod Dev 39:90-101.

Ono K, Tomasiewicz H, Magnuson T, Rutishauser U (1994) N-CAM mutation inhibits tangenital neuronal migration and is phenocopied by enzymatic removal of polysialic acid. Neuron 13:595-609.

Oppenheim RW (1996) Neurotrophic survival molecules for motoneurons: an embarrassment of riches. Neuron 17:195-197.

Ornitz DM, Xu J, Colvin JS, McEwen DG, MacArthur CA, Coulier F, Gao G, Goldfarb M (1996) Receptor specificity of the fibroblast growth factor family. J Biol Chem 271:15292-15297.

Ozawa K, Urono T, Miyakawa K, Seo M, Imamura T (1996) Expression of the fibroblast growth factor family and their receptors. Mol Brain Res 41:279-288.

Pedrosa-Domellof F, Virtanen I, Thornell LE (1995) Tenascin is present in human muscle spindles and neuromuscular junctions. Neurosci Lett 198:173-176.

Piehl F, Rurong J, Cullheim S, Hokfelt T, Lindholm D, Hughes RA (1995) Fibroblast growth factors regulate calcitonin gene-related peptide. Eur J Neurosci 7:1739-1750.

Reynolds ML, Woolf CJ (1992) Terminal Schwann cells elaborate extensive processes following denervation of the motor end plate. J Neurocytol 21:50-66.

Rich MM, Lichtman JW (1989) In vivo visualization of pre- and postsynaptic changes during synapse elimination in reinnervated mouse muscle. J Neurosci 9:1781-1805.

Rieger F, Grumet M, Edelman GM (1985) N-CAM at the vertebrate neuromuscular junction. J Cell Biol 101:285-293.
Rieger F, Nicolet M, Pinçon-Raymond M, Murawsky M, Levi G, Edelman GM (1988) Distribution and role in regeneration of N-CAM in the basal laminae of muscle and Schwann cells. J Cell Biol 107:707-719.

Rudnicki MA, Jaenisch R (1995) The MyoD family of transcription factors and skeletal myogenesis. BioEssays 17:203-209.

Rutishauser U, Grumet M, Edelman GM (1983) Neural cell adhesion molecule mediates initial interactions between spinal cord neurons and muscle cells in culture. J Cell Biol 97:145-152.

Saga Y, Yagi T, Ikawa Y, Sakakura T, Aizawa S (1992) Mice develop normally without tenascin-C. Genes Dev 10:1821-1831.

Sandrock AW, Dryer SE, Rosen KM, Gozani SN, Kramer R, Theill LE, Fischbach GD (1997) Maintenance of acetylcholine receptor number by neuregulins at the neuromuscular junction in vivo. Science 276:599-603.

Sanes JR (1995) The synaptic cleft of the neuromuscular junction. Semin Dev Biol 6:163-173.

Sanes JR (1997) Genetic analysis of postsynaptic differentiation at the vertebrate neuromuscular junction. Curr Opin Neurobiol 7:93-100.

Sanes JR, Covault J (1985) Axon guidance during reinnervation of skeletal muscle. Trends Neurosci 8:523-528.

Sanes JR, Schachner M, Covault J (1986) Expression of several adhesive macromolecules (N-CAM,L1, J1, NILE, uvomorulin, laminin, fibronectin and a heparan sulfate proteoglycan) in embryonic, adult, and denervated adult skeletal muscle. J Cell Biol 102:420-431.

Schuster CM, Davis GW, Fetter RF, Goodman CS (1996) Genetic dissection of structural and functional components of synaptic plasticity: fasciclin II controls structural plasticity. Neuron 17:655-667.

Scott LJ, Bacou F, Sanes JR (1988) A synapse-specific carbohydrate at the neuromuscular junction: association with both acetylcholinesterase and a glycolipid. J Neurosci 8:932-944.

Settles DL, Kusakabe M, Steindler DA, Fillmore H, Erickson HP (1997) Tenascin-C knockout mouse has no detectable tenascin-C protein. J Neurosci Res 47:109-117.

Slater CR (1982) Postnatal maturation of nerve-muscle junctions in hindlimb muscles of the mouse. Dev Biol 94:11-22.

Son Y-J, Thompson WJ (1995) Schwann cell processes guide regeneration of peripheral axons. Neuron 14:125-132.

Steinbach JH (1981) Developmental changes in acetylcholine receptor aggregates at rat skeletal neuromuscular junctions. Dev Biol 84:267-276.

Steindler DA, Settles D, Erickson HP, Laywell ED, Yoshiki A, Faissner A, Kusakabe M (1995) Tenascin-C knockout mice: barrels, boundary molecules, and glial scars. J Neurosci 15:1971-1983.

Tang J, Landmesser L, Rutishauser U (1993) Polysialic acid influences specific pathfinding by avian motoneurons. Neuron 8:1031-1044.

Wanaka A, Johnson EM Jr, Milbrandt J (1990) Localization of FGF receptor mRNA in the adult rat central nervous system by in situ hybridization. Neuron 5:267-281.

Wehrle B, Chiquet M (1990) Tenascin-C is accumulated along developing peripheral nerves and allows neurite outgrowth in vitro. Development 110:401-415.

Wehrle-Haller B, Chiquet M (1993) Dual function of tenascin-C: simultaneous promotion of neurite growth and inhibition of glial migration. J Cell Sci 106:597-610.

Wehrle-Haller B, Koch M, Baumgartner S, Spring J, Chiquet M (1991) Nerve-dependent and -independent tenascin-C expression in the developing chick limb bud. Development 112:627-637.

Weis J, Fine SM, David C, Savarirayan S, Sanes JR (1991) Intergration site-dependent expression of a transgene reveals specialized features of cells associated with neuromuscular junction. J Cell Biol 113:13851397. 